\title{
COLD WATER PIPE
}

By

Robert Kowalyshyn

Roderick A. Barr

January 1979

Work Performed Under Contract No. EY-76-C-02-2681

HYDRONAUTICS, Incorporated

Laurel, Maryland

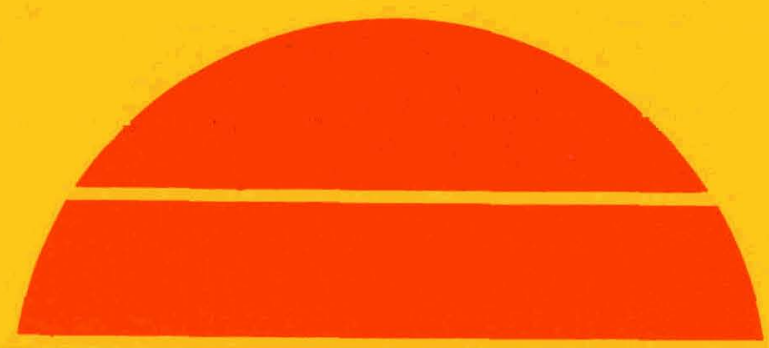

\section{U.S. Department of Energy}

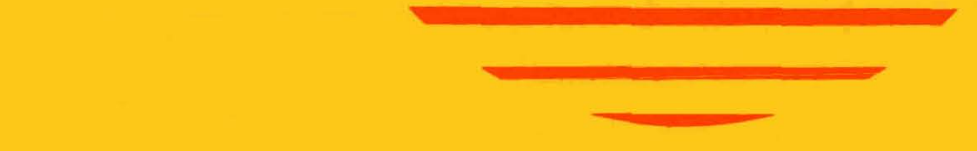




\section{DISCLAIMER}

This report was prepared as an account of work sponsored by an agency of the United States Government. Neither the United States Government nor any agency Thereof, nor any of their employees, makes any warranty, express or implied, or assumes any legal liability or responsibility for the accuracy, completeness, or usefulness of any information, apparatus, product, or process disclosed, or represents that its use would not infringe privately owned rights. Reference herein to any specific commercial product, process, or service by trade name, trademark, manufacturer, or otherwise does not necessarily constitute or imply its endorsement, recommendation, or favoring by the United States Government or any agency thereof. The views and opinions of authors expressed herein do not necessarily state or reflect those of the United States Government or any agency thereof. 


\section{DISCLAIMER}

Portions of this document may be illegible in electronic image products. Images are produced from the best available original document. 


\title{
DISCLAIMER
}

\begin{abstract}
"This book was prepared as an account of work sponsored by an agency of the United States Government. Neither the United States Government nor any agency thereof, nor any of their employees, makes any warranty, express or implied, or assumes any legal liability or responsibility for the accuracy, completeness, or usefulness of any information, apparatus, product, or process disclosed, or represents that its use would not infringe privately owned riglits. Reference herein to any epecific commerrial product, process, or service by trade name, trademark, manufacturer, or otherwise, does not necessarily constitute or imply its endorsement, recommendation, or favoring by the United States Government or any agency thereof. The views and opinions of authors expressed herein do not necessarily state or reflect those of the United States Government or any agency thereof."
\end{abstract}

This report has been reproduced directly from the best available copy.

Available from the National Technical Information Service, U. S. Department of Commerce, Springfield, Virginia 22161.

Price: Paper Copy $\$ 7.00$

Microfiche $\$ 3.50$ 
HYDRONAUTICS, Incorporated

TECHNICAL REPORT COO-2681-4

SEAKEEPING MODEL TESTS OF

A $400 \mathrm{MW}$ OTEC SPAR PLATFORM

AND COLD WATER PIPE

January 1979

By

Robert Kowalyshyn

Roderick A. Barr

(HYDRONAUTICS, Incorporated Technical Report 7513-4)

Prepared Under

DOE Contract No. EY-76-C-02-2681

(Formerly ERDA Contract E-11-1-2681) 
HYDRONAUTICS, Incorporated

\section{INTRODUCTION}

One of the most difficult problems facing the ocean thermal energy conversion (OTEC) plant designer is the design of a cold water pipe (CWP) having sufficient strength to withstand loads imposed by the ocean environment, and particularly. loads imposed by ocean waves. In order to carry out a rational CWP design, it is necessary to have accurate theoretical methods for predicting the dynamic behavior of the OTEC plant in ocean waves or a seaway.

A number of theoretical methods are currently being used to predict seakeeping behavior (behavior in a seaway) of complete OTEC plants including a platform and CWP. Validation of these methods is generally limited, due in part to the limited available test data. To date no at-sea data and only one set of model test data, Reference 1, are available for a complete OTEC plant. The primary purpose of the present and previous tests is to provide data for validation.

The tests of Reference 1 were for a design proposed for use in a one megawatt test platform, the OTEC-1. The present tests are for a potentially more representative platform design, a large ( $400 \mathrm{MW}$ ) spar type platform developed by Lockheed Missiles and Space Company (LMSC). This platform was selected for testing by the Department of Energy (DOE), in part because it, unlike the OTEC-1 design tested earlier, was an axisymmetric platform. The model CWP tested with this platform has the same diameter and length as the CWP specified by Lockheed.

The work described in this report represents the last phase of a multi-year study of OTEC plant seakeeping carried out by HYDRONAUTICS, Incorporated for DOE under Contract No. EY-76-C-02-2681 (originally ERDA Contract E-11-1-2681). Earlier work under this contract is described in References 1-3. 


\section{DESCRIPTION OF TEST PROGRAM}

The model test program was designed to provide a maximum amount of information. The tests: were designed to provide validation data for various cases including the spar platform alone and with a CWP having widely varying attachment stiffnesses. Tests were carried out for the following configurations:

1. Spar alone

2. Spar with CWP free in pitch and roll

3. Spar with CWP rigidly attached

The details of the spar, CWP and CWP attachment geometric characteristics are discussed in detail in the next section.

Tests were carried out for three sea states modeling random, long-crested (uni-directional) waves with significant (average of one-third highest) wave heights of 15, 25, and 35 feet. Characteristics of these waves are given in Table 1 . The random wave motions spectra were used, together with wave energy spectra, to obtain motion response amplitude operators (RAO's) which give response as a function of wave frequency. Such RAO's provide a far more meaningful basis for validating predictions than do the statistical values (RMS or significant motions) usually derived from random wave tests. In this report, the primary comparisons are made for RAO's.

It was not possible in the tests to fully reproduce the desired Pierson-Moskowitz wave energy spectra for the $15,25$. and 35 foot significant wave heights specified by DOE. It was felt, however, that the spectra used were suitable for present purposes. Figure 1 shows a comparison of the desired spectra and the spectra used in the model tests. The differences in desired and actual spectra will affect statistical results for a given sea state but will have no significant effect on RAO's deduced from the tests. 
HYDRONAUTICS, Incorporated

$-3-$

TABLE 1

CHARACTERISTICS OF TEST WAVES

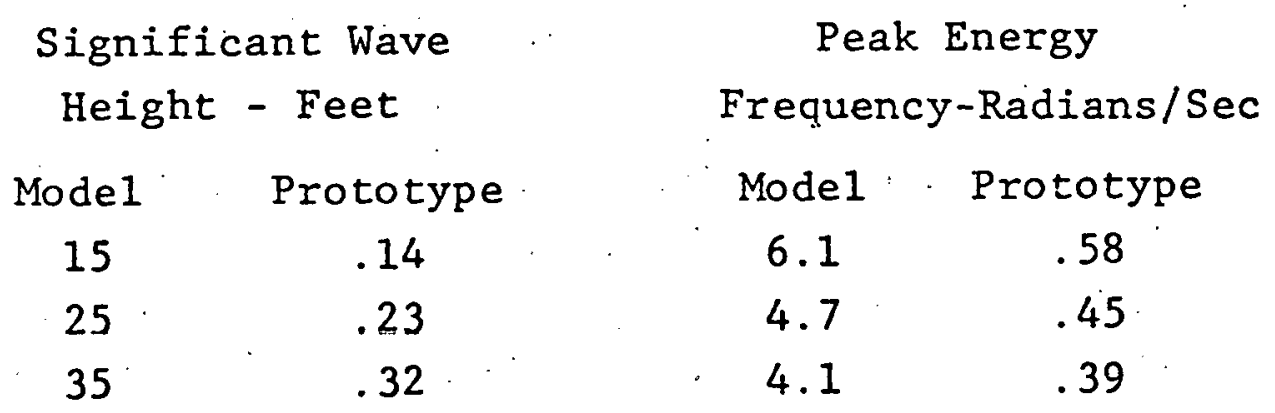


HYDRONAUTICS, Incorporated

MODEL DESCRIPTION

The model of the spar platform and CWP were built to a linear scale ratio of 110 . The platform model was built from a set of general arrangement plans prepared by Earl and Wright and provided by Lockheed Missiles and Space Company (No. 770932 $1 \& 2$ ).

The spar model shown in Figure 2 was constructed of closed cell foam, aluminum pipe and plywood. The core consisted of foam sections shaped and glued to a plywood base. Inside the core was a cavity which contained the lead ballast necessary to give the correct weight and suitable pitch and roll radii of gyration. The eight external modules were formed from sections of standard eight inch aluminum pipe. In order to facilitate floating and trimming the model at the design waterline, an air bladder system was used. This consisted of bladders secured in four of the modules with valves that could be reached from above the surface of the water. By adjusting the volume of air in these bladders, the model could easily be trimmed. An inclining experiment was performed on the platform to determine its actual metacentric height. Table 2 gives the principal characteristics of the model as built and the scaledup values for the prototype.

The CWP model diameter was selected to scale the 80 foot inside diameter of the Lockheed CWP. The CWP model was built of glass reinforced plastic (GRP). It was built in four sections of approximately equal length in order to allow installation of three strain gage bending moment flexures along its length. Each section was layed up using one layer of fiberglas cloth in order to achieve the minimum possible stiffness. The sections were then wound in. a spiral pattern with fiberglas roving, as shown in Figure 3, to increase buckling strength without increasing bending stiffness. 
HYDRONAUTICS, Incorporated

The flexures used to measure bending moments were identical to those used to measure bending moments used in the earlier OTEC-1 tests and incorporated four active element bridges in two perpendicular bending moment axes corresponding to the transverse and longitudinal axes on the model. The geometry of the strain gages provides temperature compensation and eliminates interactions between the two bending moment axes or between bending moment and axial or torsional loading. Figure 4 shows a flexure installed in the CWP.

The CWP was tested with two types of connections to the platform. One was a pivot free in pitch and roll (see Figure 5), the other was a rigid connection consisting of a flexure similar to that in Figure 4. Figure 6 shows the geometry of the pipe and its flexures. The principal characteristics for the model CWP and the scaled up prototype are given in Table 3.

Figure 7 shows the details of the mooring array used to locate the spar model in the model basin. The apparatus used to position this array consisted of a circular ring 16 feet in diameter with vertical posts reaching into the water with pulleys attached to the submerged end. The mooring lines ran from the platform through these pulleys and then up to mooring spring units located above the water. The pulleys were located so as to allow the mooring lines to run horizontally from the model's vertical center of gravity. Figure 8 shows the model moored in place for testing. 
HYDRONAUTICS, Incorporated

TABLE 2

CHARACTERISTICS OF MODEL SPAN PLATFORM AND SCALED-UP PROTOTYPE PLATFORM

Characteristic

Displacement - Long Tons

Water in Modules

No Water in Modules

Overall Diameter - Feet

Center Body Diameter - Feet

Module Diameter - Feet

Draft - Center Body - Feet

Draft - Modules - Feet

Surface Piercing Column

Diameter - Feet

Gyradius about

Pitch - Feet

Yaw - Feet

Metacentric Height - Feet

Vertical Center of Gravity

Below WL - Feet
Model

0.483

0.179

3. 1.60

2.270

0.725

3.010

3.880

.300

1.076

0.895

0.048

2.19
Prototype

643,000 238,000 347.6

249.7

79.8

331.1

426.8

33.0

118.4

98.4

5.3

240.6 
HYDRONAUTICS, Incorporated

$$
-7-
$$

CHARACTERISTICS OF MODEL CWP AND SCALED-UP PROTOTYPE CWP

Characteristic.

Overal1 Length - Feet

CWP Section Length - Feet

Flexure Section Length - Feet

Mean Diameter - Feet

Wa11 Thickness - Feet

Modulus of Elasticity

CWP Section - psi

Flexure Section - psi

$E I$ - CWP Section - Pound $F t^{2}$

$\mathrm{EI}$ - Flexure Section - Pound $\mathrm{Ft}^{2}$

Total Weight in Air - Lbs

Total Weight in Water
Mode1

26.833

6.146

0.5

0.725

0.001125

$1.382 \times 10^{6}$

$10.6 \times 10^{6}$

$1.61 \times 10^{4}$

$1.10 \times 10^{3}$

23.98

5.75
Prototype

2951.7

676.1

55.0

79.75

0.1238

$152 \times 10^{6}$

$2.60 \times 10^{14}$

$1.77 \times 10^{13}$

$3.19 \times 10^{7}$

$7.65 \times 10^{6}$ 
HYDRONAUTTICS, Incorporated

$$
-8-
$$

\section{TEST FACILITY DESCRIPTION}

A11 tests were conducted in the HYDRONAUTICS Ship Model Basin which is equipped with a deep well which was used in these tests. The principal dimensions of the basin and deep well are:

Basin

$\begin{array}{lr}\text { Length } & 414 \mathrm{ft} .11 \mathrm{in} . \\ \text { Width } & 24 \mathrm{ft} .11 \mathrm{in.} \\ \text { Water Depth } & 11 \mathrm{ft} .6 \mathrm{in} .\end{array}$

Deep Well

Diameter

$11 \mathrm{ft} .0 \mathrm{in}$.

Depth (from water surface)

$41 \mathrm{ft} .6 \mathrm{in.}$

Distance from wavemaker

$322 \mathrm{ft} .5 \mathrm{in.}$

Distance from beach

$92 \mathrm{ft} .6 \mathrm{in.}$

The CWP was located at the center of the deep well for all tests. 
HYDRONAUTICS, Incorporated

\section{TEST PROCEDURES}

Determination of Cold Water Pipe Characteristics

In order to measure the stiffness (EI) of the CWP, a simple beam bending experiment was carried out on a test section of glass reinforced plastic pipe. It was the original intention to perform the experiment on an actual section of the CWP model, however, due to local deformation in the section when loaded, it was impossible to obtain accurate results in this manner. Instead, a foam filled section of pipe with a much smaller diameter was used.

The test section was formed of one layer of fiberglas cloth molded into a $32^{\prime \prime}$ long by 1.7" diameter pipe. This was then filled with foam to reduce buckling. It was felt that the foam would not contribute significantly to the bending stiffness. This section was then supported on knife edges spaced 30" apart. A series of known weights were applied midway between the supports and the deflection measured. From the known loads, deflections and dimensions of the pipe, the modulus of elasticity of the pipe was calculated. This modulus of elasticity was then used to determine the.stiffness (EI) for the full size model CWP.

Free Oscillation

Free Oscillation tests in heave and pitch were conducted for the spar without CWP. The primary purpose of these tests was to determine the spar natural frequencies and damping ratios to check the predicted spar hydrodynamic forces. The same basic procedure was used for both tests. The output of the motion sensing transducer for the motion measured was used to produce a strip chart time history. The natural periods were determined by analyzing the response of the model after an initial offset was applied for the motion in question. Care was taken to achieve pure heave or pitch offsets; however, some offset in the other motions was unavoidable. 
HYDRONAUTICS, Incorporated

Seakeeping Tests

For the seakeeping tests 6 to 14 channels of data were recorded. All transducers produced a voltage analog of the quantity measured which was recorded on a magnetic tape recorder. For all seakeeping tests, wave height and five motions (heave, pitch, roll, surge, sway) of the spar model were measured. Yaw was neglected since there were not enough channels to accommodate six motions and four bending moment flexures. Yaw was considered the least significant of the six motions. The wave height transducer was a capacitance wave probe. The wave height probe was located 22 feet ahead of the model CG to minimize measurement of reflected waves from the model. The five motions of the spar model were measured with a light weight pantograph rig which can be seen in Figure 8. Potentiometers were used as transducers for the five motions measured. For tests with the CWP model freely attached to the spar by a pivot, six more channels were added. They were the longitudinal and transverse bending moments in the cold water pipe at three locations. The transducers for these measurements were the bending moment flexures described previously. When the CWP was rigidly attached to the spar model, a fourth flexure was added in place of the pivot at the top of the CWP. Figure 6 shows the location of these flexures on the pipe.

The following procedure was used to conduct all seakeeping tests. After waiting between 15 and 25 minutes after the preceding run to allow the waves from the preceding run to die out, "zeros" were recorded on the magnetic tape of each of the data channels. After this, the HSMB wavemaker was programmed to produce the desired irregular waves and started. It was then necessary to wait for the sea state to become fully developed over the deep well where these tests were conducted. This waiting period was calculated for each wave based on the velocity 
HYDRONAUTICS, Incorporated

of its shortest component. At the end of this waiting period, the magnetic tape recorder was started and data was recorded for approximately 120 seconds. Approximately 100 seconds of these data were digitized.

Data Reduction Procedures

The magnetic tape recorder used to record the data has the capability of playing back the data being recorded with a short time delay. This allowed the data to be processed as each run: was being made. For selected channels, strip chart time histories were made: The primary purpose of these was to verify the transducer outputs during the run.

\section{TABLE 4}

COMPARISON OF DIFFERENT DIGITIZING FREQUENCIES

\begin{tabular}{|c|c|c|c|}
\hline$:$ & 10.0 & 5.0 & (\% Diff.) \\
\hline Wave $\mathrm{Ht}$. & .268 & .263 & 1.9 \\
\hline Surge & .084 & .087 & 3.4 \\
\hline Heave. & .096 & .103 & 6.8 \\
\hline Pitch, & .934 & .737 & 26.7 \\
\hline BM 非. & 34.691 & 34.281 & 1.2 \\
\hline BM 非2 & 35.970 & 35.607 & 1.0 \\
\hline$B M \quad$ 非3 & 35.058 & 34.696 & 1.0 \\
\hline BM 非 & 42.441 & 41.258 & 2.9 \\
\hline
\end{tabular}


HYDRONAUTICS, Incorporated

The voltage analog of the data which was played back from the tape recorder was run through an analog to digital converter and into a computer. The A-D converter sampled the data at a rate of $5 \mathrm{~Hz}$ and these points were sorted in a file by the computer. Since the center of gravity was well below the water surface it was not possible to measure the platform motions at the center of gravity. For this reason the sorted digital data was processed by a program that transformed the data to an axis system with origin at center of gravity and stored the resulting digital data in a separate file.

The transformed motion data and the bending moment data were analyzed using a spectral analysis program which generated power density spectra. A second program was then used to calculate an RAO from these spectra and the measured wave power density spectrum.

It was determined that $5 \mathrm{~Hz}$ was an acceptable rate at. which to digitize the data. Table 4 shows a comparison of test results digitized at both 5 and $10 \mathrm{~Hz}$. There were no significant differences between the results except for pitch. In the case of pitch, while the percent difference between the two results is large, the actual magnitudes are very small and the observed differences are approaching possible errors inherent in the measuring instruments. The accuracy of the measurements is discussed in detail below.

Accuracy of Measurements

In order to aid in the interpretation of the model test data, estimated instrumentation accuracy is provided in Table 5. This table deals separately with two distinct areas of the measurement accuracy problem. The first is the maximum possible error that can be expected in any measurement. This error 
HYDRONAUTICS, Incorporated

arises from two sources. The first is the maximum observed: deviation from the best straight line fit to the calibration data. The second is the maximum error to be expected from the record/playback process using the magnetic. FM tape recorder used to store the data. This latter value is provided by the tape recorder manufacturer.

The second type of error is signal threshold, or the smallest signal that. can be measured. This threshold is a function of the tape recorder used for data storage and is supplied by the manufacturer. For each type of transducer used, Table 5 lists typical sensitivity, maximum calibration deviation, maximum tape recorder error, maximum error converted to physical units, tape recorder threshold and tape recorder threshold converted to physical units. 
HYDRONAUTICS, Incorporated

\section{PRESENTATION OF RESULTS}

The results of this study are presented in the form of response amplitude operators and significant (average of onethird highest) amplitudes for random waves. Test results are also compared with theoretical predictions made for the exact conditions of the model test.

Response amplitude operators (RAO's) for the three model configurations (HMB alone and with the two CWP's cases described earlier) and for head and beam waves are given in Figures $9-24$. Each figure presents the ratio of surge (sway) and heave amplitude to wave amplitude, pitch (roll) angle amplitude to wave slope and, except for the spar above, CWP bending moment amplitude divided by wave amplitude. Each figure presents results for all three sea states.

Figures 25 - 40 present comparisons of the measured and predicted RAO's. The theoretical predictions were made using recently developed methods described in Reference 4.

Tables 6 - 8 present measured and predicted significant (average of one-third highest) motion, CWP relative motion and CWP bending moment amplitudes (one-half peak-to-peak values) for the random wave tests. All results are given for prototype scale. It should be noted that the CWP bending moments are for the scaled-up model CWP, which does not represent a proposed CWP design for the spar. 
HYDRONAUTICS, Incorporated

\section{CALCULATED RESULTS}

It was decided to make theoretical predictions of the seakeeping behavior of the spar platform/CWP for comparison with the measured results. These predictions were made using the new CWP analysis programs developed by Hydronautics for NOAA/DOE, Reference 4, and estimated platform hydrodynamic data.

Predictional Methods

The methods used to make the theoretical predictions of platform/CWP seakeeping behavior are described in detail in Reference 4. These methods incorporate the new CWP analysis methods developed for NOAA/DOE and the coupled platform/CWP methods developed previously for DOE, Reference 3. A brief description of these methods' is given below.

The CWP analysis methods permits separate analysis of CWP static and dynamic bending and extensive responses, including response to regular and irregular ocean waves, to ocean current and to current induced unsteady flows. In the present study no current was considered and only the dynamic response of the coupled platform/CWP to a specified seaway was considered.

The computer programs CWPFLX and XOTEC described in Reference 4 permit calculation of the coupled response of an axisymmetric platform and a CWP when platform hydrodynamic force data (added mass, damping and wave exciting forces) are provided as an input to program XOTEC. These programs calculate platform motions and distributions along the CWP length of CWP lateral displacement, shear forces and stresses and bending moments and stresses, for both regular waves and irregular, long-crested waves.

Calculations were made for the exact model platform and CWP characteristics described in Tables 2 and 3. 
HYDRONAUTICS, Incorporated

Hydrodynamic Data

As the present spar platform does not resemble any of the platforms considered by Hydronautics under previous studies for DOE, References 3,5 , and 6 , the available body of hull hydrodynamic data was used to estimate platform added mass, damping and wave exciting forces. In view of the complex shape of the platform this procedure is probably as accurate as any method except a fully three-dimensional method such as that of Garrison, Reference 7. The effort and cost required to use Garrison's program would be great, however, since a minimum of several hundred surface panels would be required to accurately represent the platform geometry.

The selection of CWP added mass and damping data for high Reynolds numbers are discussed in some detail in References 4 and 8 . The present tests involve Reynolds number of the order of $10^{5}$, and hence results for that Reynolds number should be used. The model CWP was relatively rough, and data for roughness-diameter ratios of $10^{-3}$ to $10^{-4}$ were considered appropriate.

The data of Sarpkaya, Reference 9 , indicate that an inertia coefficient of 1.8 , or an added mass coefficient of 0.8 is appropriate. It is difficult to estimate an appropriate drag coefficient from the data of Reference 9 or from other sources due to the sensitivity of drag coefficient to Reynolds number, roughness and amplitude of motion. Based on the data a quadratic drag coefficient of 1.5 was selected and uscd with a representative rms CWP amplitude to determine the equivalent linearized CWP damping used in program CWPFLX. 
TABLE 6

SIGNIFICANT MOTION AMPLITUDES

FOR PLATFORM ALONE

Sea State

$\begin{array}{lrcc}\text { (Sig. Wave Ht./Ft.) } & .14(.146)^{*} & .23(.224)^{*} & .32(.312)^{\star} \\ \text { Surge (Ft.) } & .071 & .093 & .123 \\ \text { Heave (Ft.) } & .048 & .101 & .275 \\ \text { Pitch (Ft.) } & 1.061 & 1.468 & 1.826 \\ & & . & \\ \text { * First numbers are nominal values, numbers in parentheses are } \\ \text { values determined for the actual test. }\end{array}$

TABLE' 7

' PLATFORM AND CWP WITH PIN CONNECTION

SIGNIFICANT MOTION AND BENDING MOMENT AMPLITUDES

Sea State

$\begin{array}{lrrr}\text { (Sig. Wave Ht./Ft.) } & .14(.162) & .23(.219) & .32 \text { (.329) } \\ \text { Surge (Ft.) } & .062 & .101 & .131 \\ \text { Heave (Ft.) } & .050 & .093 & .168 \\ \text { Pitch (Ft.) } & 1.271 & 1.101 & 2.628 \\ \text { BM \#1 (Ft./Lb.) } & 13.530 & 10.916 & 15.950 \\ \text { BM \#3 (Ft./Lb.) } & 8.494 & 15.790 & 26.249 \\ \text { BM \#\#4 (Ft./Lb. } & 12.763 & 13.851 & 19.354\end{array}$

- TABLE 8

- PLATFORM AND CWP WITH RIGID CONNECTION

SIGNIFICANT MOTION AND BENDING MOMENT AMPLITUDES

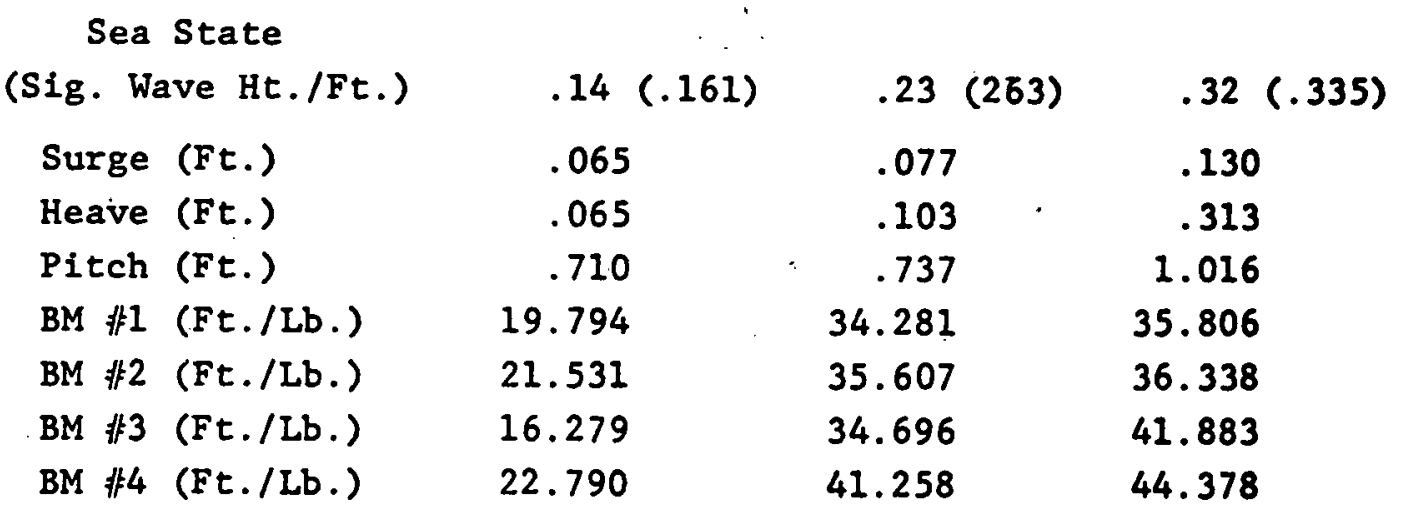


HYDRONAUTICS, Incorporated

\section{DISCUSSION OF RESULTS}

The model test data exhibit, as a whole, two important features; a general lack of scatter and some clear non-linearities. Model test results and comparisons between measured and predicted are discussed in detail below.

Model. Test Response Amplitude Operators (RAO's)

The RAO's derived from the irregular wave tests are given in Figures 10-24. Figures 10-12 give results for the spar alone; Figures 13-17 give results for the spar with pin connected CWP; and Figures 18-24 give results for the spar with rigidly connected CWP.

The motions of the spar alone show significant non-linearity, particularly for surge and heave, for prototype frequencies of 0.5 radians per second or less. At higher frequencies there is no clear non-linearity. The existence of non-linear response is not surprising since wavemaking (1inear) damping is reduced by the deep draft and viscous (non-linear) damping is increased by the use of the external modules. Motions are generally significant only for frequencles less than 0.5 radians per second.

The motions of the spar with pin connected CWP are similar to those for the spar alone. Surge and pitch motions are not measurably effected by the presence of the CWP. The smaller heave motions with the CWP are due to the reduced heave natural frequency resulting from heaving of the water column within the CWP. Approximately 650 pounds of water will move with the CWP, resulting in about a 20 percent reduction in heave natural frequency and about 30 to 40 percent reductions in heaving motion at a given frequency. This is the magnitude of the reduction observed in the data.

The surge and heave motions for the spar with rigidly connected CWP are similar to those for the spar with pin connected CWP. The surge motions are slightly less with the rigidly 
HYDRONAUTICS, Incorporated

connected CWP. The pitch motions with rigidly and pin connected CWP's are quite different. The pitch motions are generally less with rigidly connected CWP except around a frequency of $0.5 \mathrm{rad}-$ ians per second, a CWP modal frequency, where increased pitch motions occur due to large exciting forces from the CWP. This effect of the CWP on pitch motions is not surprising in view of the large moment at the top of the CWP at this frequency (see Figure 21).

The bending moments for the pin connected CWP indicate modal frequencies at about 0.67 radians per second and at a frequency somewhat below 0.3 radians per second. The bending moments at positions. 2 and 4 (25 and 75 percent of the length down the CWP, respectively) show a sharply peaked response at about 0.67 radians per second, while the bending moment at position 3 (50 percent of length down the (WP) shows only a slight peak. It is thus concluded that for this CWP mode, positions 2 and 4 are near anti-nodes while position 3 is near a node. The responsc at 0.67 radians per second shows a clear non-linearity; results at other frequencies generally show a clear, but less obvious non-linearity.

The bending moments for the rigidly connected CWP are quite different than those for the pin connected CWP. One CWP modal frequency occurs at a frequency of about 0.52 radians per second, while a second modal frequency probably occurs at a frequency near 0.2 radians per second. Bending moments at all four locations show a sharp peak at 0.52 radians per second. While there are clear non-linearities, particularly at the 0.52 radian per second modal frequency, these are not as large as those for the pin connected CWP. The maximum bending moments (about 350 poundfeet per foot) are more than twice the maximum bending moments with the pin connected CWP. 
HYDRONAUTICS, Incorporated

Model Test Significant Responses in Irregular Waves

The significant (average of one-third highest) response amplitudes (one-half peak-to-peak values) are given in Tables 6 , 7 and 8 . These tables present model motions and CWP bending moments in feet, degrees and pound-feet for each of the three sea states. The actual measured significant wave heights are shown for each casê.

For the spar alone, Table 6, surge and pitch motions increase roughly in proportion to wave height, while heave motions vary roughly as the square of significant wave height. This large variation in heave motion with wave height appears to be due to the large influence of low frequency heave motions, as discussed below.

The significant motions of the spar with pin connected CWP are generally similar to those for the spar alone. Surge motions are nearly identical, as would be expected from the RAO's. Heave motions are smaller with the CWP, particularly for the larger wave heights, a result which is also expected from the RAO's. Pitch motions are somewhat larger with the CWP, particularly for the largest wave height; this seems plausible based on the RAO's at the corresponding peak energy frequency of 0.39 radians per second.

The significant surge motions for the spar with rigidly attached CWP are similar to those for the other cases. The heave motions are, surprisingly, larger than those for the spar without CWP. The pitch motions are significantly smaller than those for the other cases, a result that follows from the pitch RAO's. The significant bending moments for the pin connected CWP clearly reflect the influence of the 0.67 radian per second modal frequency. The large bending moments at locations 2 and 4 for the smallest wave height reflect the similarity of the peak energy frequency ( 0.58 radians per second) and the modal frequency. 
HYDRONAUTICS, Incorporated

The small bending moment at location 3 for the small wave height reflect the absence of any large response at the CWP modal frequency (see Figure 16).

The significant bending moments for the rigidly connected CWP, reflect the influence of the 0.52 radian per second modal frequency. The bending moments for the middle wave height. (0.263 feet) are comparable to those at the large wave height ( 0.335 feet) due to the close correspondence of the maximum wave energy frequency for the middle wave height ( 0.49 radians per second) and the CWP modal frequency.

Lateral Responses

In theory the platform and CWP should have no response in the direction normal to wave direction. In reality some lateral motions are unavoidable due to model assymetries, wave degradations, etc. In almost all cases, lateral motions (sway and roll) were 10 to 20 percent of motions in the wave direction (surge and pitch). These motions were thus not significant and are not presented in the report. CWP lateral bending moments were all between 10 and 35 percent of bending moments in the wave direction, the smaller percentages being associated,with the larger values of bending moments. These bending moments appear to be due primarily to the lateral motions and are not presented in the report.

Scaling of Bending Moments

The bending moment data in the figures are given in model scale since the model CWP does not represent a specific CWP design. It is instructive, however, to assume a prototype CWP and to determine the scaled bending moments and stresses for this CWP design.

For scaling purposes a steel CWP was assumed. This 79.75 foot diameter steel CWP would have wall thickness, moment of inertia and section modulus of 0.62 feet, 124000 feet $^{4}$ and 3100 feet ${ }^{3}$, respectively. Bending moment scales as scale ratio cubed 
HYDRONAUTICS, Incorporated

and hence the prototype CWP bending moment and bending stress, $M_{p}$ and $\sigma_{p}$, are:

$$
\begin{aligned}
M_{p} & =1.331 \times 10^{6} M_{m} \text { pound-feet } \\
\sigma_{p} & =2.98 \mathrm{M}_{\mathrm{m}} \mathrm{psi}
\end{aligned}
$$

where $M_{m}$ is model bending moment in pound-feet. From the RAO's, the maximum model bending moment is about 300 pound feet per foot of wave height. The corresponding maximum prototype CWP stress is about 900 psi per foot of wave amplitude; this value seems quite moderate for a CWP modal frequency and a rigidly attached, quite stiff CWP. Table 9 presents model and corresponding scaled significant bending moments for the irregular seas, for two locations for both the rigidly and pin connected CWP's. The maximum value of prototype significant bending moment is $6.5 \times 10^{9}$ pound-feet which corresponds to prototype CWP stress of about 15,000 PSI.

Influence of Drift Motions on Responses

As noted above, the measured significant heave motions for the spar alone and the spar with rigidly attached CWP appear inconsistent. It was felt that this inconsistency might be due to the influence of significant low frequency and static drift motions of the spar.

It was observed during all lests that operation in waves produced a net reduction of up to 0.2 feet in mean draft; this is presumably due to a net second order suction or drift force such as experienced by submarines operating near the free surface in waves. In addition, all of the motions energy spectra, such as the heave spectrum shown in Figure 25, show a distinct energy at very low frequencies (less than about one radian per second model scale or 0.1 radians per second prototype scale). This energy is assumed to correspond to a response to low frequency drift forces produced by the irregular waves. This energy may be increased by the correspondence of the natural frequency of 
HYDRONAUTICS, Incorporated

\section{TABLE 9}

Measured Model and Scaled Prototype Significant

Bending Moment Amplitudes for Irregular Seas

Significant Wave Height-Feet Model Prototype

$\begin{array}{ll}0.14 & 15.4 \\ 0.23 & 25.3 \\ 0.32 & 35\end{array}$

$0.32 \quad 35$

Significant Wave Height-Feet Model Prototype
0.14
15.4
0.23
25.3
0.32
35

a. Pin Connected CWP

Significant Bending Moment-Pound Feet Location 3 Model Prototype $/ 10^{9}$ Model Prototype/109

$\begin{array}{rrrr}8.49 & 1.24 & 12.76 & 1.87 \\ 15.79 & 2.31 & 13.85 & 2.03 \\ 26.25 & 3.84 & 19.35 & 2.83\end{array}$

b. Rigidly Connected CWP

Significant Bending Moment-Pound Feet Location 2 Model Prototype/10 Model Prototype/109

$\begin{array}{llll}21.53 & 3.15 & 22.79 & 3.34 \\ 35.61 & 5.21 & 41.26 & 6.04 \\ 36.34 & 5.32 & 44.38 & 6.50\end{array}$

3.15

5.32 Location 4 $22.79 \quad 3.34$ 44.38 6.50 
HYDRONAUTICS, Incorporated

the platform/mooring system and these low frequency drift forces. The estimated model surge natural frequency for the moored spar is, for example, about 0.65 radians per second.

In order to determine the influence of the low frequency response on platform motions, the heave significant responses were redetermined using a lower cut-off frequency of 2.0 radians per second (model scale). Table 10 presents a comparison of significant heave motions for the three test cases and sea states, determined with and without the energy cut-off. The motions determined with the cut-off are one-quarter to one-half those determined without cut-off, indicating the large impact of the low frequency motions, and these motions show much mure consistent trends with wave height and with CWP attachment.

Based on these results it is concluded that the significant motions should not be used for validation. The effects of low frequency drift motions are not included in the RAO's and hence the RAO's should be used for all validation studies.

TABLE 10

Significant Heave Motions Determined With and Without Low Frequency Cut-off

Nominal Wave Significant Heave Motion-Feet Height-Feet

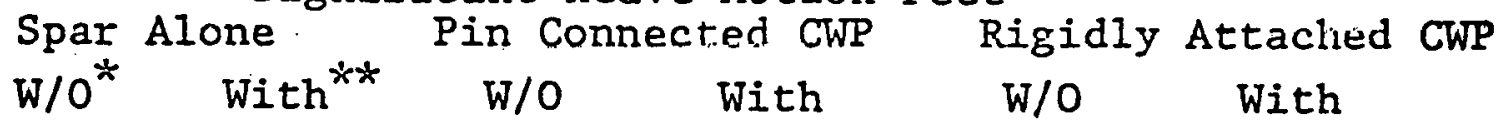
0.14
0.048
0.019
0.050
0.021
0.065
0.018
0.23
0.101
0.050
0.093
0.039
0.103
0.043
0.32
0.275
0.086
0.168
0.073
0.313
0.073

* W/O - Without low frequency cut-off of energy

** WITH - With low frequency cut-off of energy 
Free Oscillation Tests

Figure 26 shows traces of platform heave and pitch motions from free oscillation tests resulting from initial heave and pitch displacements of the platform alone.

The heave trace shows no characteristic frequency as the response was highly damped. The model failed to return to its initial draft following both positive and negative initial displacements. This was probably due to the fact that the static restoring force (about 0.25 pounds for the initial 0.06 foot change in draft) was less than the sticktion in the seakeeping rig.

The pitch trace shows a more normal behavior with a model natural frequency of 0.43 radians per second and an average damping ratio of 0.113 . The damping ratio is essentially constant, indicating little non-linearity for the three degree and less pitch angles occurring in the test. Based on the measured properties of Table 2 and the extimated pitch added mass the model pitch natural frequency was estimated to be 0.48 radians per second. This is quite close to the measured value of 0.43 . Comparison of Measured and Predicted Platform Motions

Figures 27-29 present a comparison of the measured and predicted motions of the spar platform with no CWP. It can be seen that the predicted and measured motions are in excellent agreement. This agreement resulted in part from some adjustments to the theoretically-empirically predicted surge-pitch coupling terms and wave exciting forces for frequencies greater than 0.6 radians per second.

Figures 30-32 present a comparison of the measured and predicted motions of the platform with rigidly attached CWP. It can be seen that the predicted and measured motions are in generally excellent agreement. The only exceptions are the surge and pitch motions at the highest frequency of 0.8 radians per second. These 
HYDRONAUTICS, Incorporated

differences at 0.8 radians per second, which are of small absolute magnitude, are probably due to the extreme sensitivity of spar motions to cross-coupling terms ( $A_{15}$, etc.), a sensitivity which is increased by the addition of the CWP. A difference of five percent in the $A_{15}$ term will produce a change of 50 percent or more in surge and pitch at 0.8 radians per second. It is concluded because of this sensitivity, that the spar platform is probably not a good choice for validation studies, even though the spar has small motions and CWP loads.

Comparison of Measured and Predicted Bending Moments

Figures 33-36 present a comparison of the measured and predicted CWP bending moments for the case of the rigidly attached CWP. These calculations are based on a CWP damping appropriate to the 25 foot significant wave height except for the peak response frequency of 0.5 radians per second. For this frequency, the equivalent linearized damping was based on an estimated amplitude of motion of about 0.40 feet (model scale). Ideally, the damping for each frequency should be selected to match CWP motions or velocity at that frequency.

The calculated and measured bending moment RAOs are in generally good agreement. The agreement is best for locations 2 and 4 , where the largest peak bending moments occur. The agreement is worst at the top of the CWP (location 1); the reason for the absence of a significant peak in bending moment. at this location is not known, although it may be due to greater than predicted stiffness of the attachment at the top of the CWP. The calculated responses for frequencies greater than 0.6 radians per second are generally much larger than the measured bending moments at the higher frequencies. It seems likely that a significant source of these differences is errors in estimated platform cross-coupling coefficient and motions, as discussed in the previous section. This certainly warrants further study. 
HYDRONAUTICS, Incorporated

One possible source of errors in the calculated bending moments is the determination of the CWP stiffness (EI). The stiffness was determined in several ways and the best results were used in the calculations. The stiffness of the upper flexureattachment section was not separately determined. 
HYDRONAUTICS, Incorporated

CONCLUSIONS

Based on the model test results and the comparisons of measured and predicted results a number of conclusions seem worthy of note. These include:

1. The model test results show good consistency and lack of scatter. Results for different sea states are in generally good agreement, except for well defined non-linearities. 2. The motions data show some clear non-1 inearities at lower frequencies while the bending moment data show significant non-linearities, particularly at and near CWP modal frequencies.

3. The motions energy spectra show significant energy at very low frequencies, apparently due to resonant response of the moored spar to low frequency, second-order drift forces. 4. There was a significant reduction in spar operating draft during operation in waves, apparently due to a steady, second-order suction forces such as that effecting submarines. 5. The spar motions and CWP bending moments are generally quite small, indicating good potential performance of the spar as an OTEC platform.

6. The calculated and measured spar motions are generally in excellent agreement.

7. The calculated and measured CWP bending moments are generally in good agreement, although there are several significant differences which warrant further study.

8. Based on comparisons of the calculated and measured results, it is concluded that the new DOE/NOAA elastic beam methods do give satisfactory prediction of coupled spar/CWP behavior in ocean waves.

9. The spar does not appear to be the best type of platform to use for validating theoretical method due to its sensitivity to small changes in coefficients, CWP loads, etc. 
HYDRONAUTICS, Incorporated

REFERENCES

1. Sheldon, L. R., R. A. Barr and J. D. O'Dea, "Model Tests of OTEC-1 - Tests of HMB With and Without Cold Water Pipes," HYDRONAUTICS, Incorporated Technical Report C00-2681-2, December 1977.

2. Barr, R. A., J. F. O'Dea and V. Ankudinov, "Theoretical Evaluation of the Seakeeping Performance and Resistance/ Propulsion Characteristics of Five Candidate OTEC Platforms," HYDRONAUTICS, Incorporated Technical Report COO-2681-1, July 1976.

3. Barr, R. A., P. Murphy and V. Ankudinov, "Theoretical Evaluation of the Seakeeping Behavior of Large OTEC Plant Platform and Flexible Cold Water Pipe Configurations." HYDRONAUTICS, Incorporated Technical Report C00-2681-3, August 1978 (currently under review).

4. Barr, R. A., P. Y. Chang and C. Thasanatorn, "Methods for and Examples of Dynamic Load and Stress Analysis of OTEC Cold Water Pipe Designs," HYDRONAUTICS, Incorporated Technical Report 7825-2, November 1978.

5. Barr, R. A., P. Murphy and V. Ankudinov, "Calculated Seaway Responses of Six Candidate OTEC Platforms," HYDRONAUTICS, Incorporated Technical Report 7812-2, November 1977.

6. Barr, R. A., P. Murphy and P. Majumdar, "Theoretical Seakeeping Studies for a Tuned Sphere OTEC Plant," HYDRONAUTICS, Incorporated Technical Report 7780-1, October 1977.

7. Garrison, C. J., "Hydrodynamic Interaction of Waves with a Large Displacement Floating Body," U.S. Naval Postgraduate School Report NPS $-69 \mathrm{Gm} 770091$ prepared under Interagency Agreement E(49-26)-1044, September 1977.

8. Hove, D., W. Shih and E. Albano, "Hydrodynamic Design Loads for the OTEC Cold Water Pipe," Science Applications, Inc. Report SAI-79-559-LA, September 1978.

9. Sarpkaya, T., "In-Line and Transverse Forces on Cylinders in Oscillatory Flow at High Reynolds Numbers," Journal of Ship Research, Volume 21, No. 4, December 1977. 


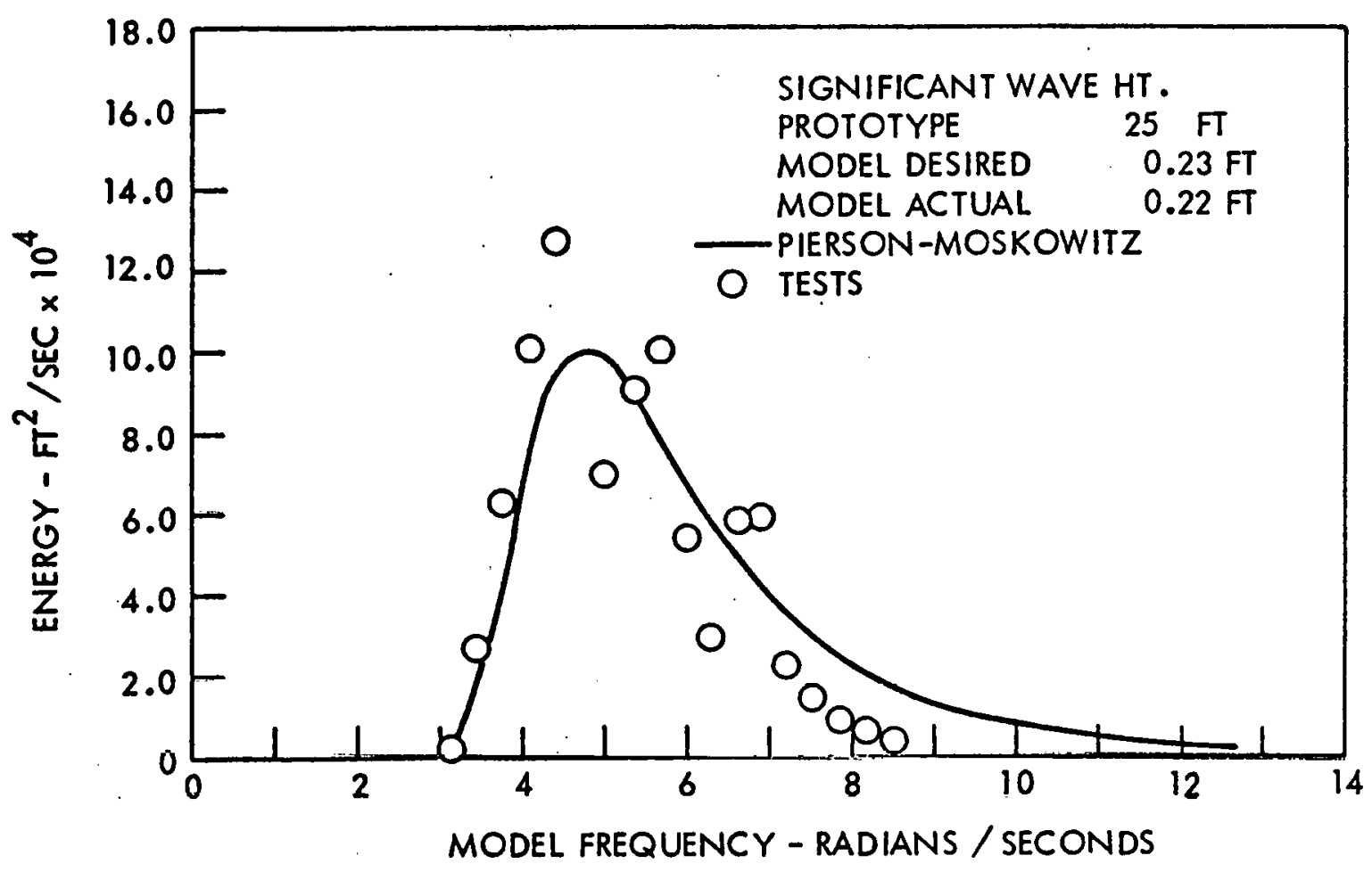

a. 25 FOOT PROTOTYPE SIGNIFICANT WAVE HEIGHT

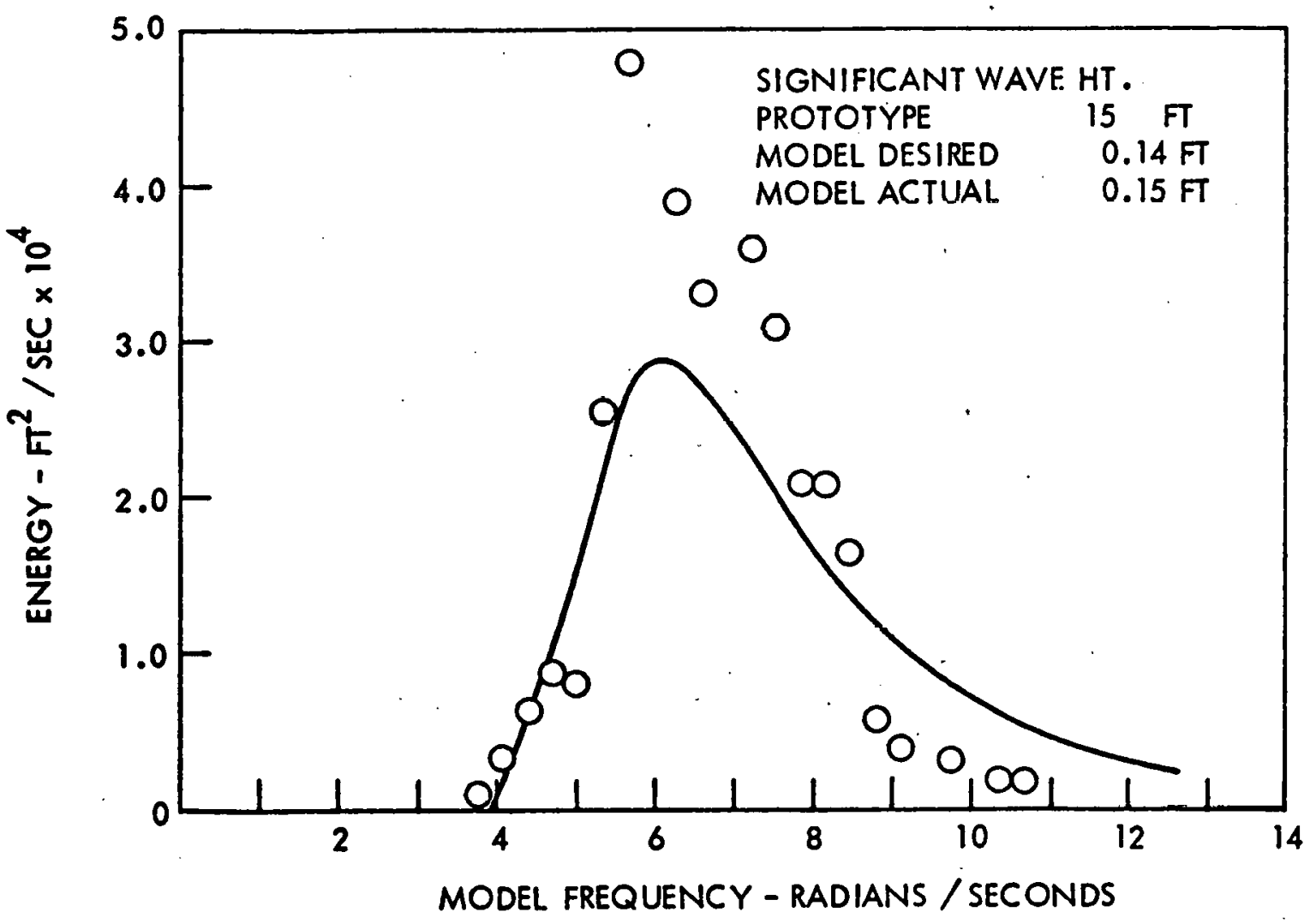

b. 15 FOOT PROTOTYPE SIGNIFICANT WAVE HEIGHT

FIGURE. I - DESIRED AND MEASURED WAVE ENERGY SPECTRA 
HYDRONAUTICS, INCORPORATED

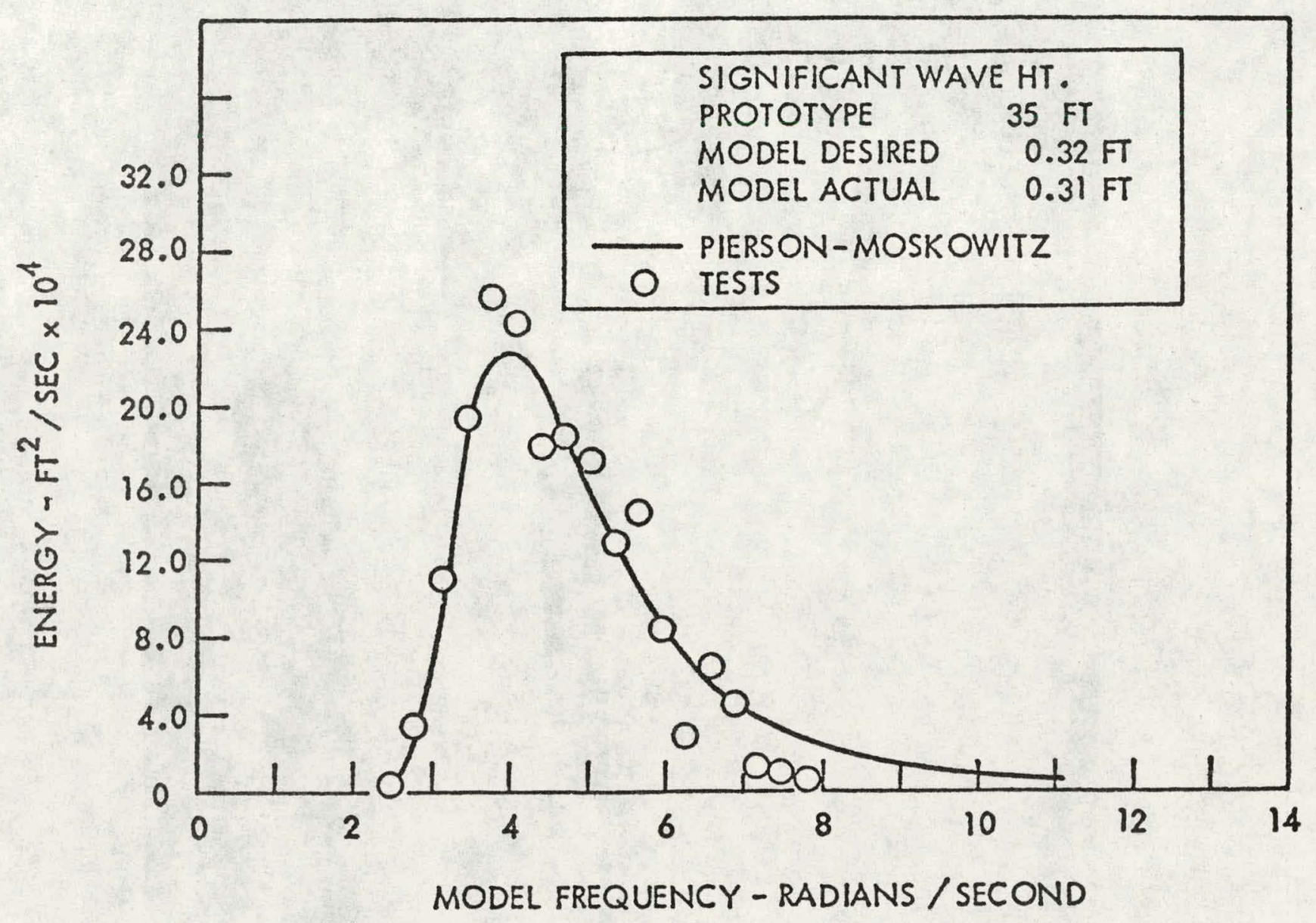

c. 35 FOOT SIGNIFICANT WAVE HEIGHT

FIGURE I CONCLUDED 
HYDRONAUTICS, INCORPORATED

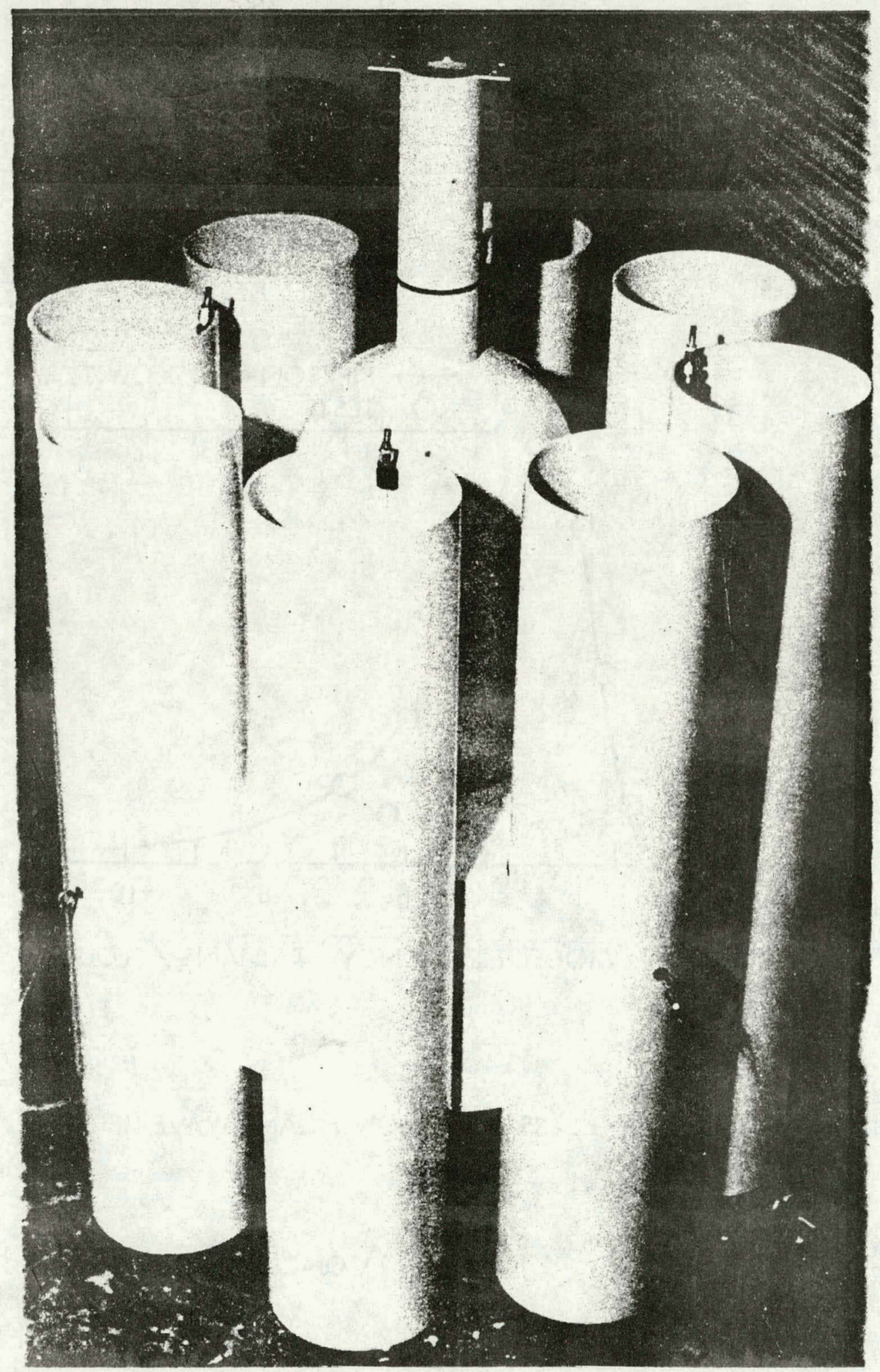

FIGURE 2 - MODEL OF SPAR PLATFORM 


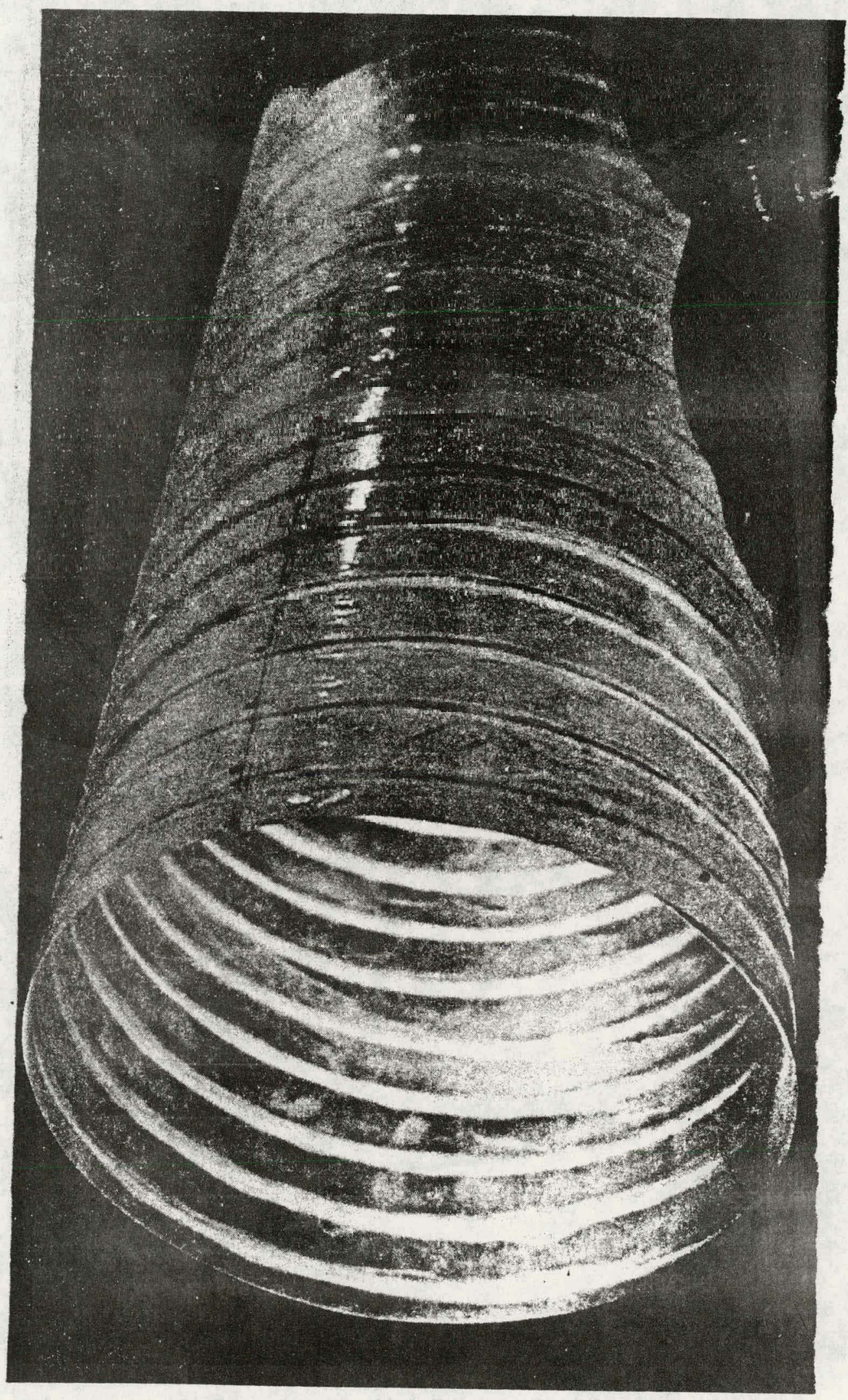

FIGURE 3 - SECTION OF CWP MODEL 


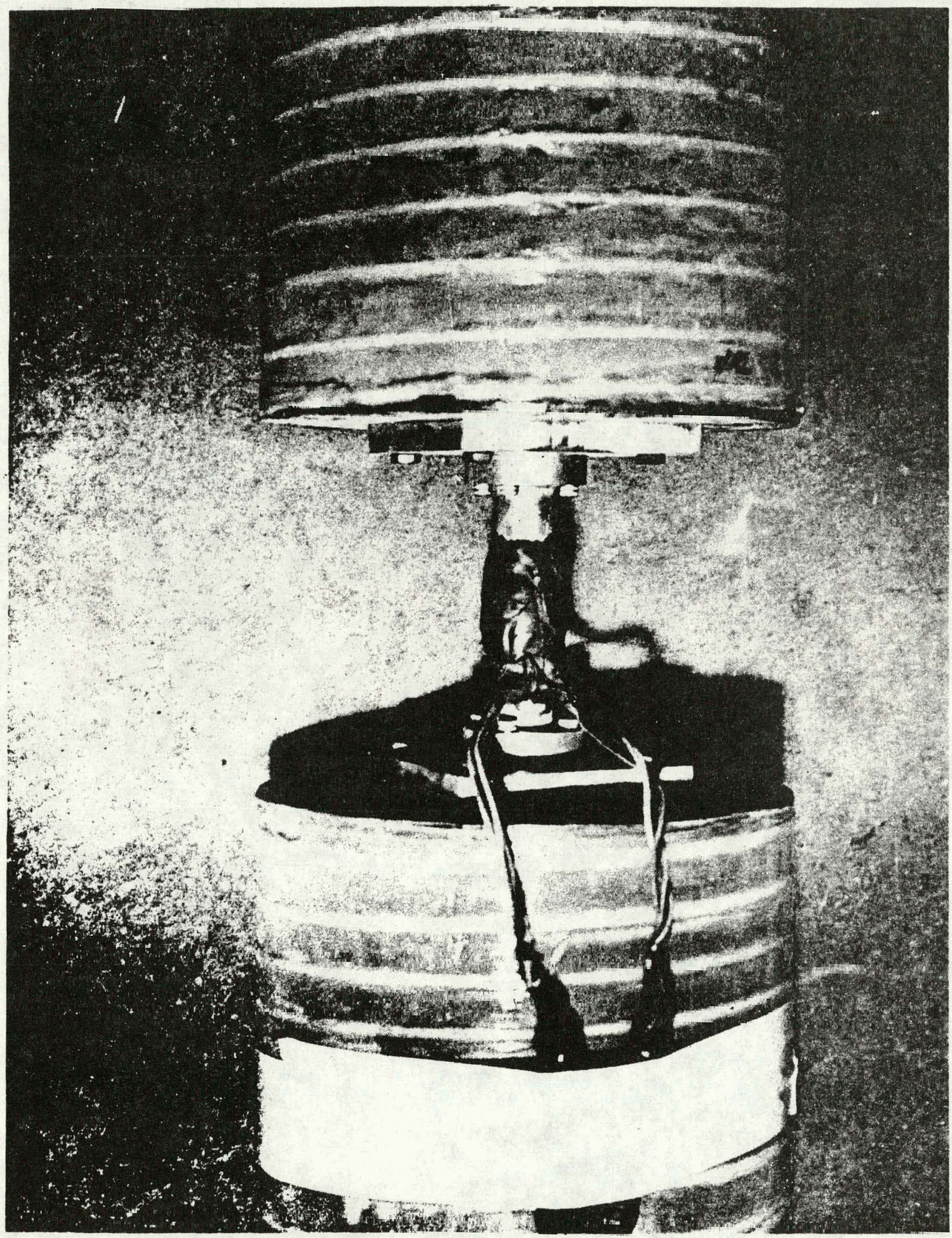

FIGURE 4 - PHOTOGRAPH OF A SECTION OF THE MODEL CWP SHOWING A TYPICAL BENDING MOMENT FLEXURE MOUNTED IN PLACE 


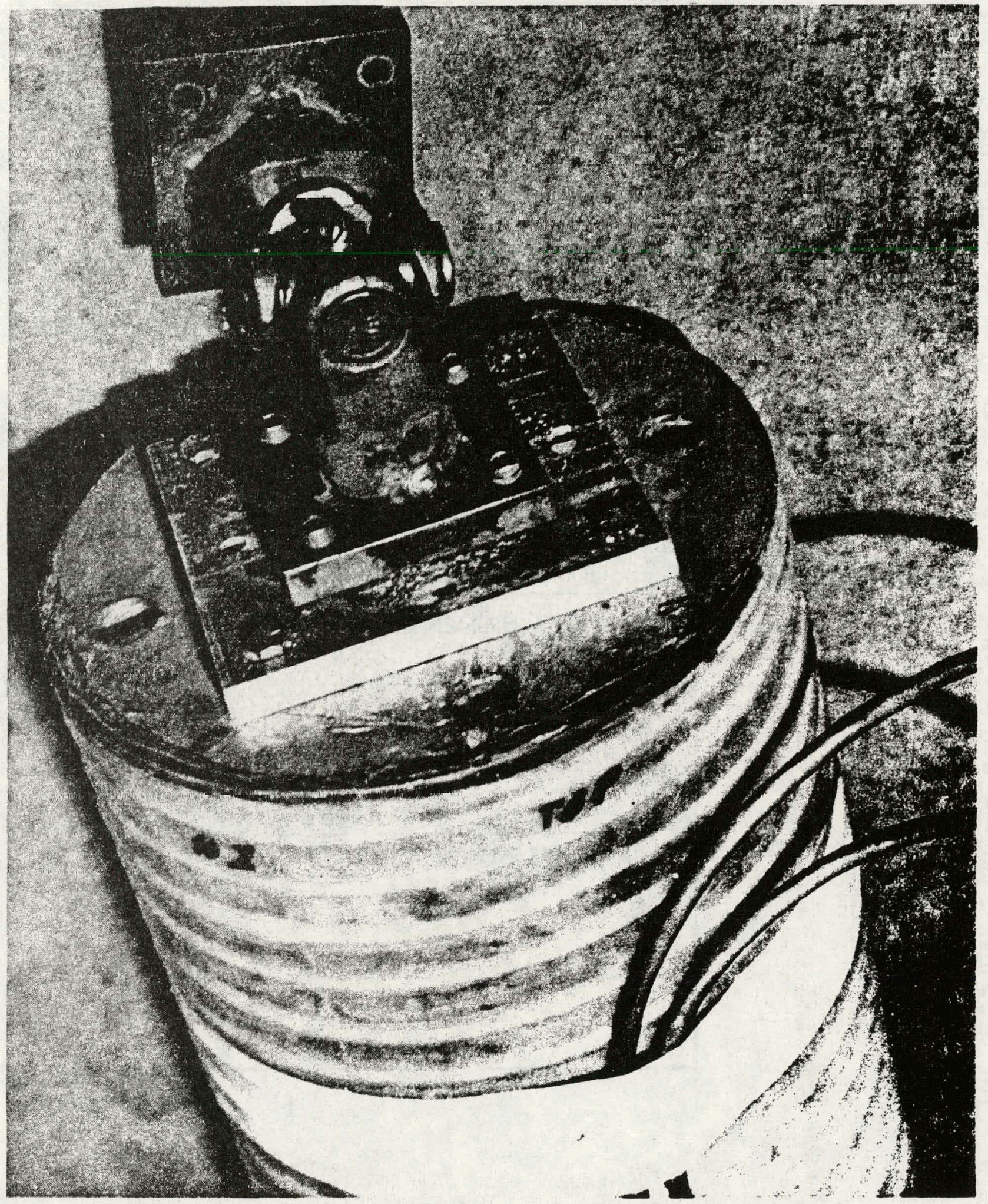

FIGURE 5 - PHOTOGRAPH SHOWING THE PIN CONNECTION FOR THE MODEL CWP 
HYDRONAUTICS, INCORPORATED

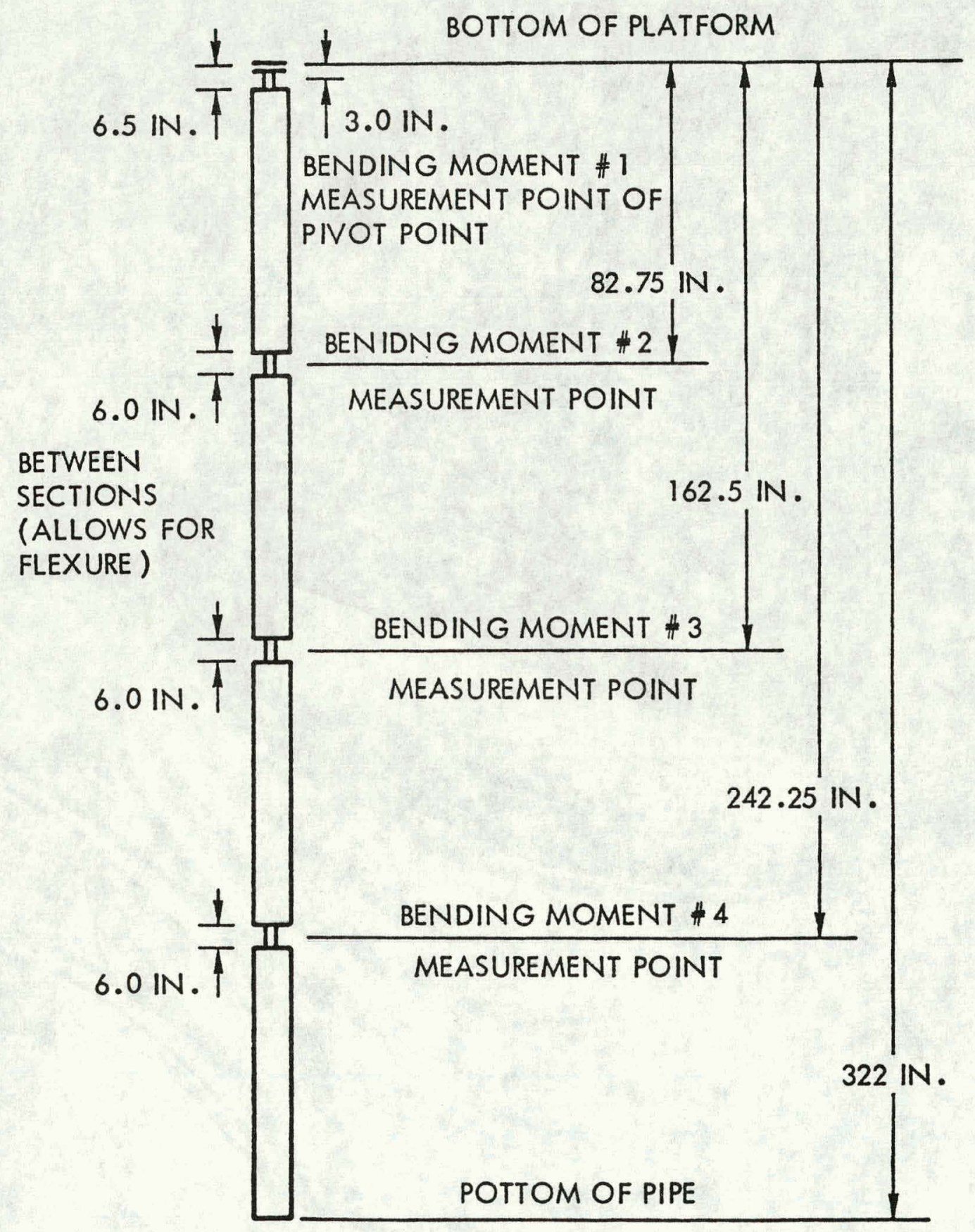

FIGURE 6 - GEOMETRY OF COLD WATER PIPE 

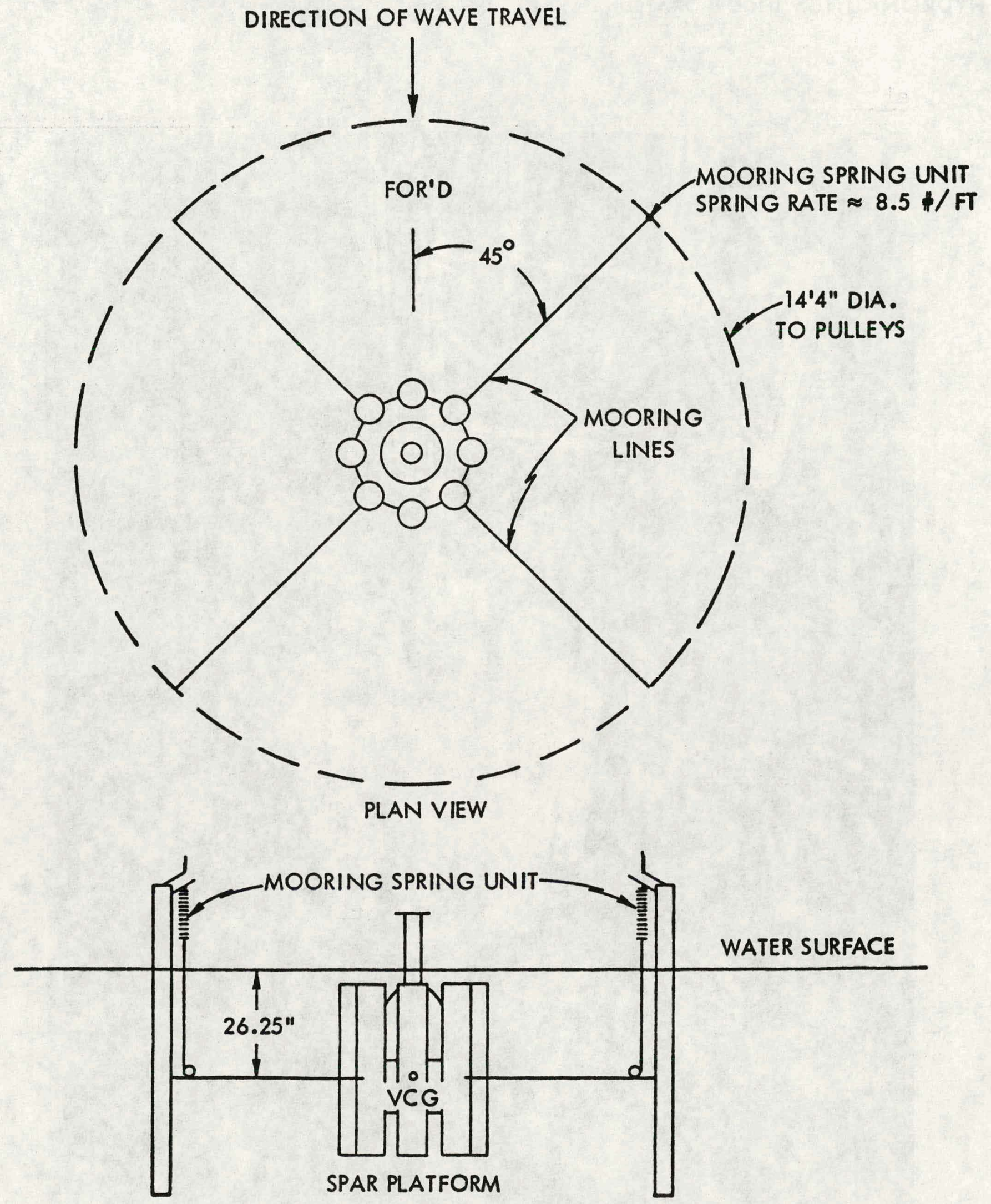
HYDRONAUTICS, INCORPORATED

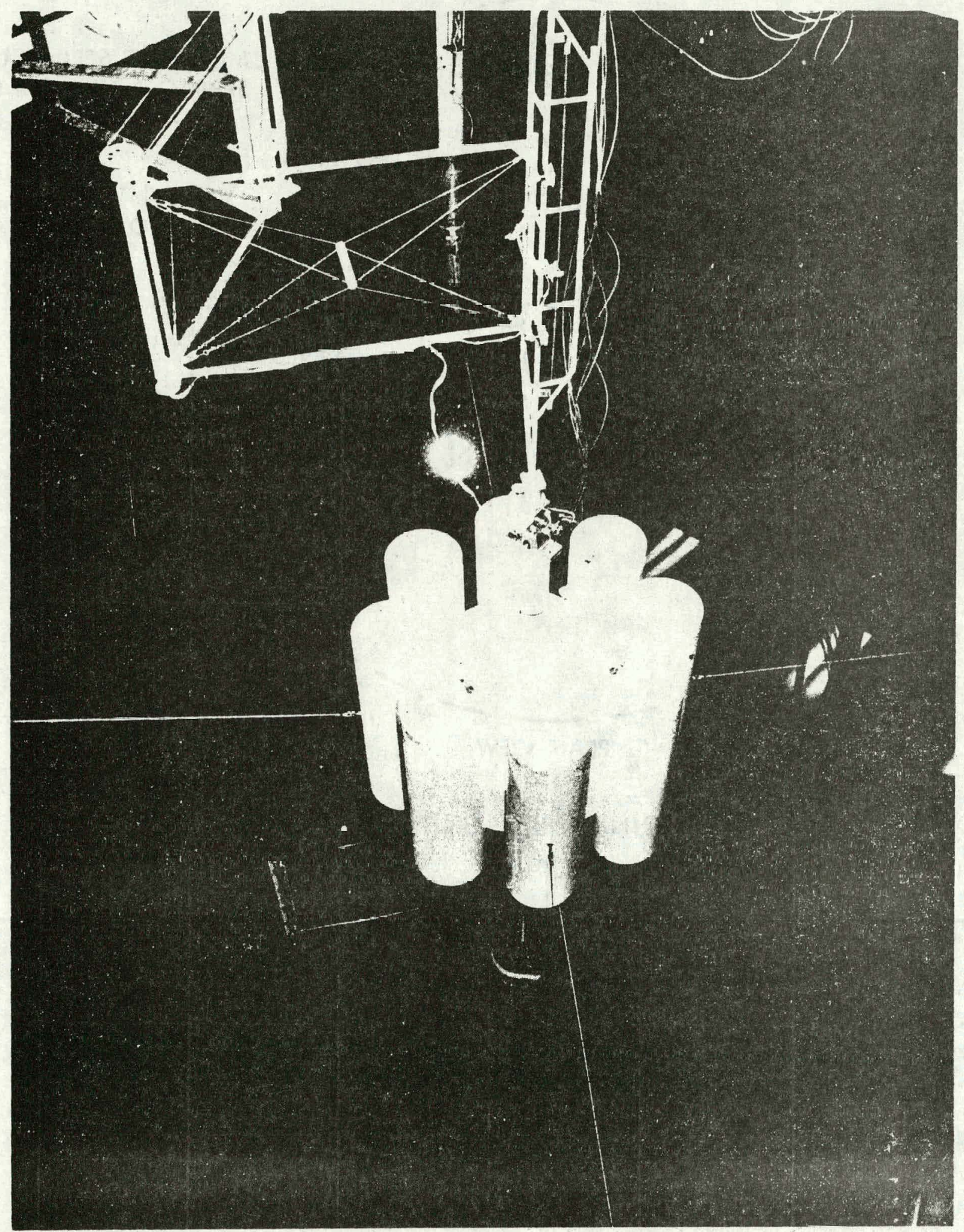

FIGURE 8 - TEST SETUP IN HYDRONAUTICS SHIP MODEL BASIN SHOWING SPAR, CWP, MOORINGS AND PART OF SEAKEEPING RIG 


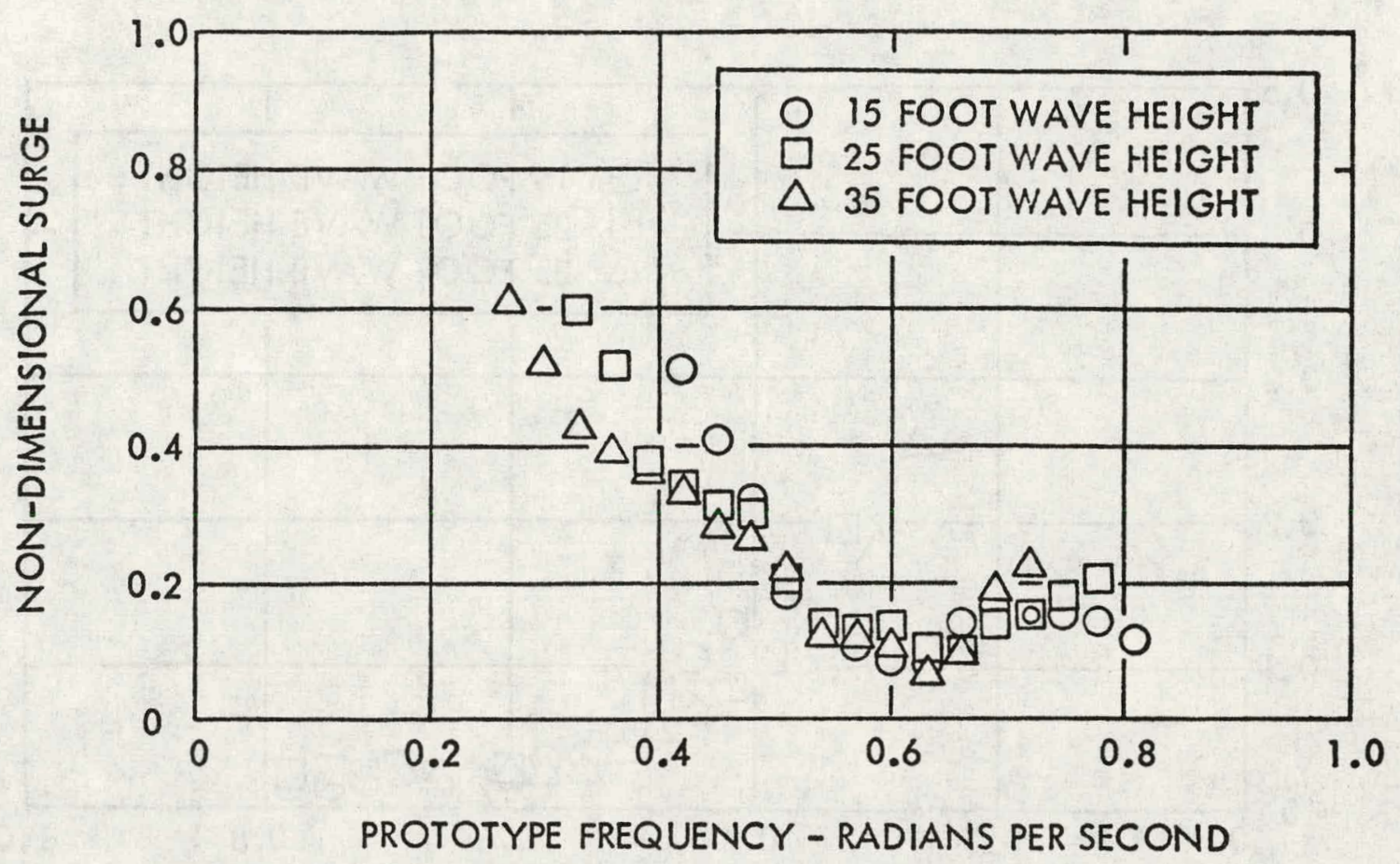

FIGURE 9 - MEASURED RAOS FOR SURGE - SPAR WITHOUT CWP

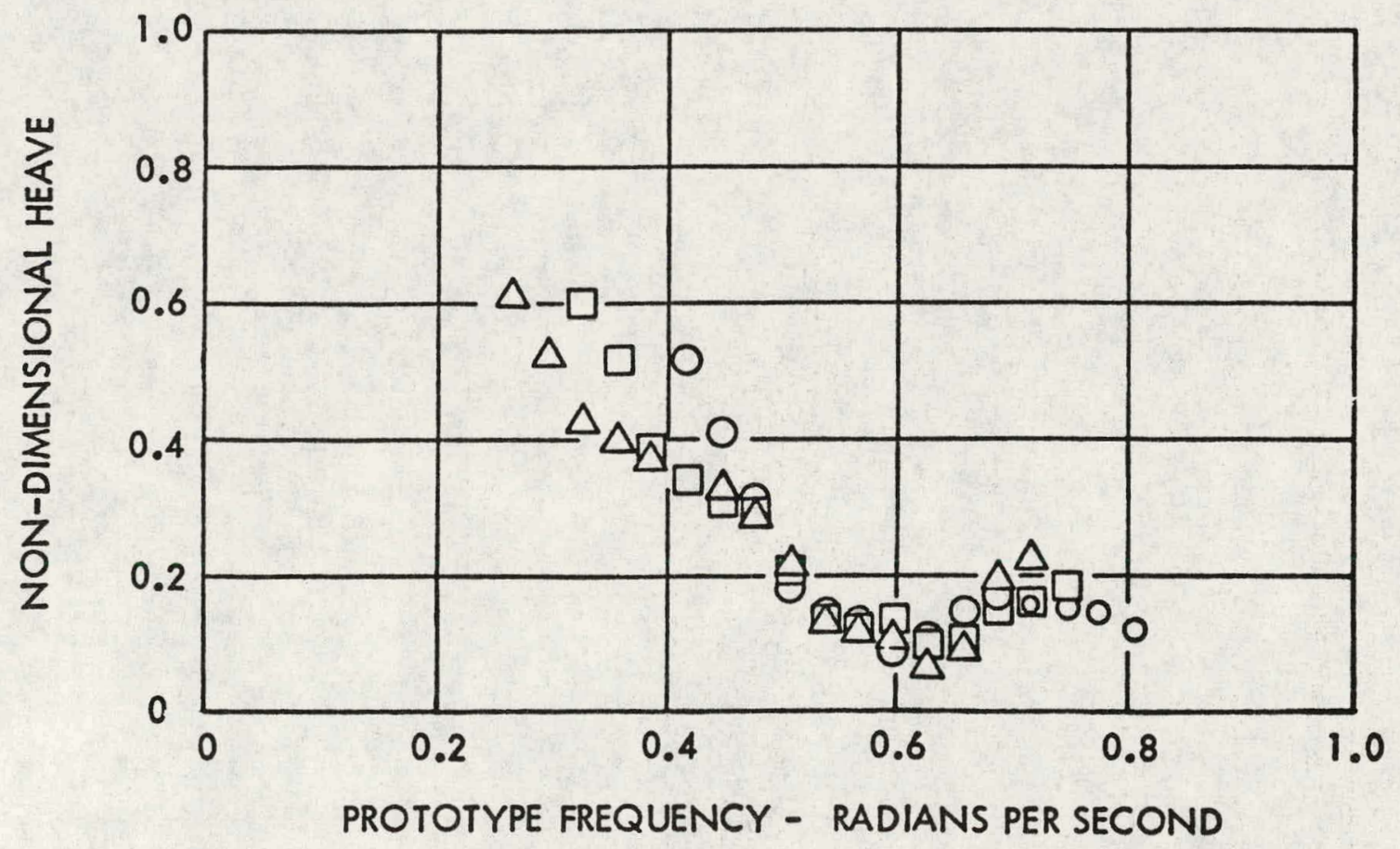

FIGURE 10 - MEASURED RAOS FOR HEAVE - SPAR WITHOUT CWP 
HYDRONAUTICS, INCORPORATED

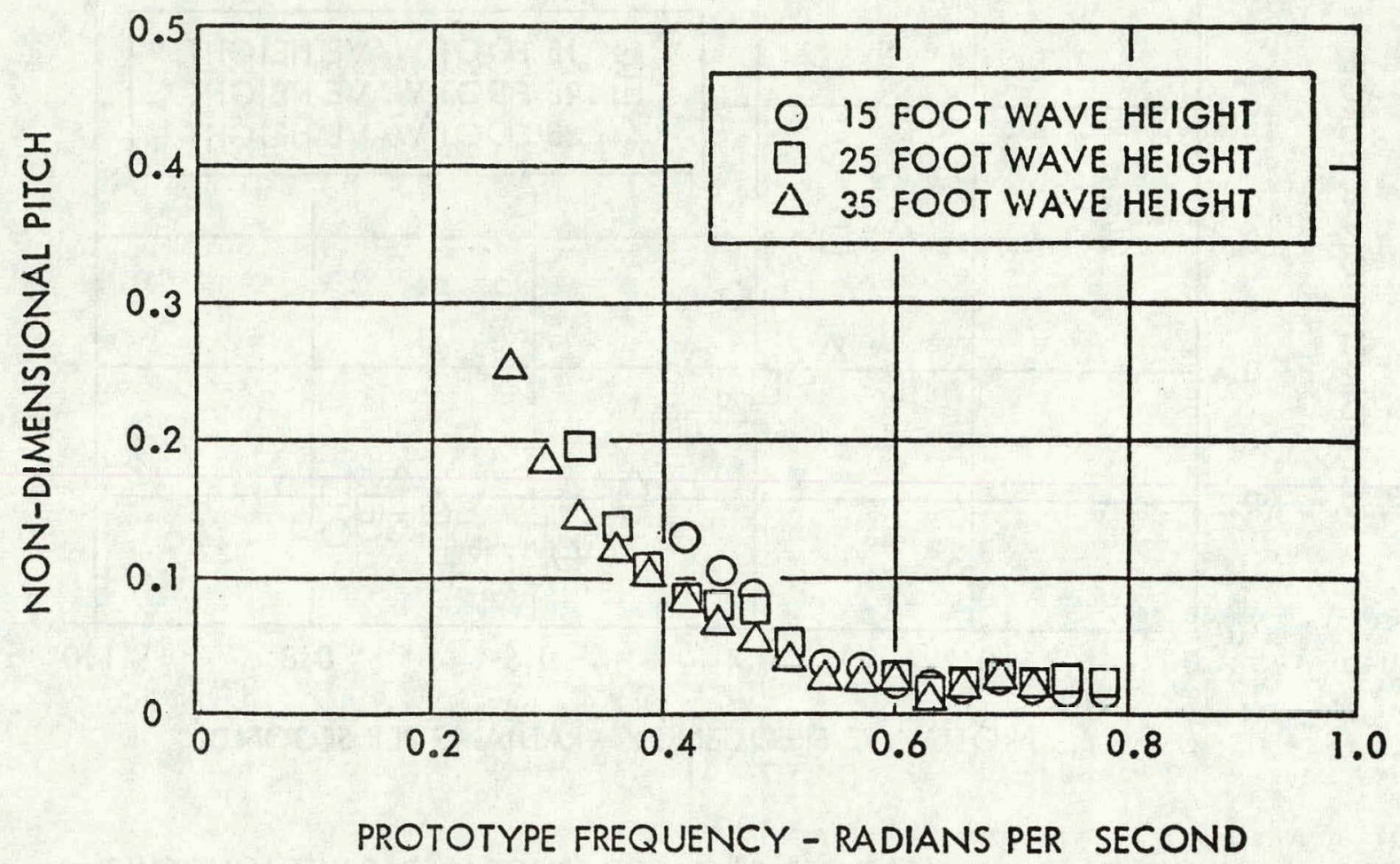

FIGURE 11 - MEASURED RAOS FOR PITCH - SPAR WITHOUT CWP 


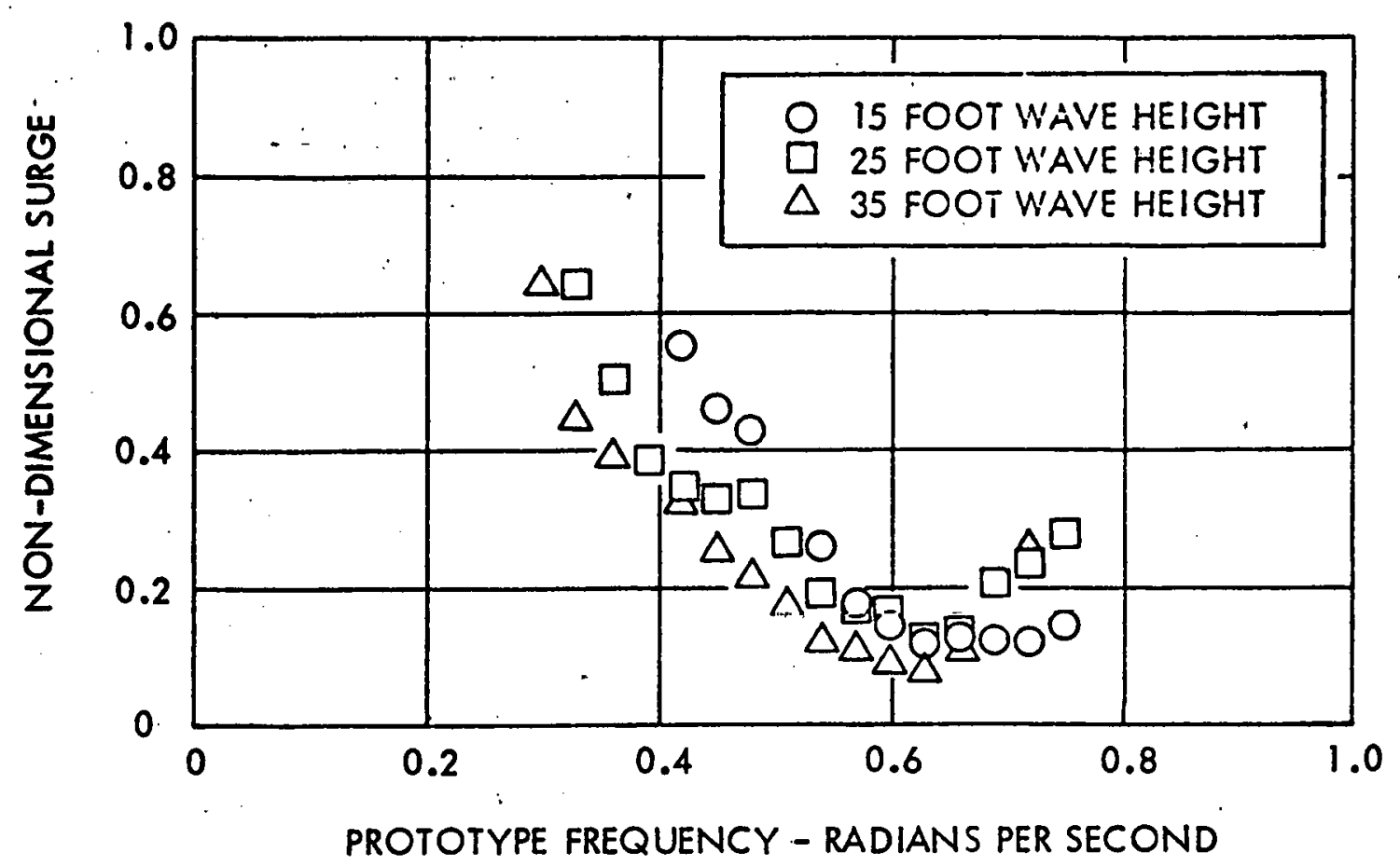

FIGURE 12 - MEASURED RAOS FOR SURGE - SPAR WITH PIN CONNECTED CWP

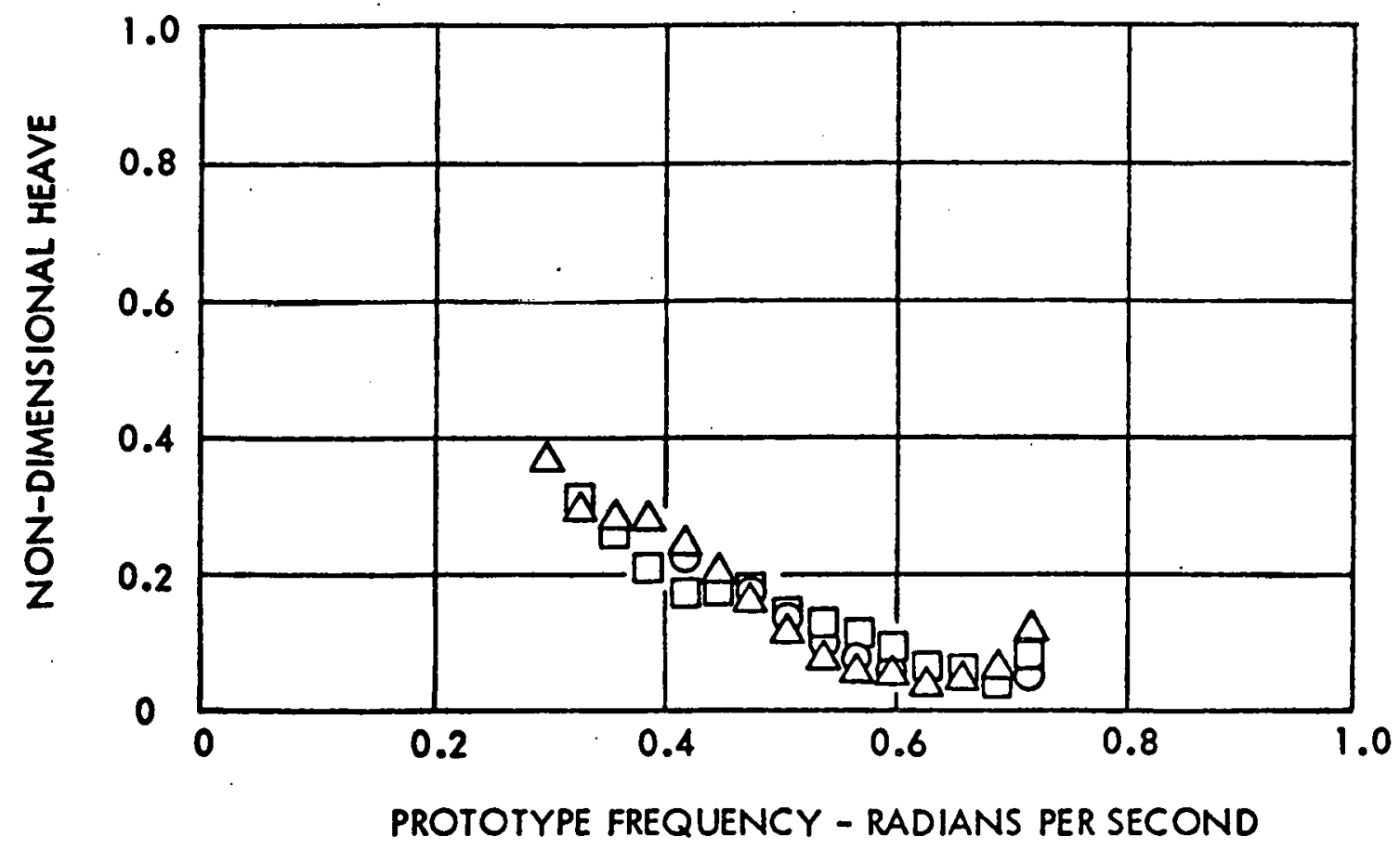

FIGURE 13 - MEASURED RAOS FOR HEAVE - SPAR WITH PIN CONNECTED CWP 


\section{HYDRONAUTICS, INCORPORATED}

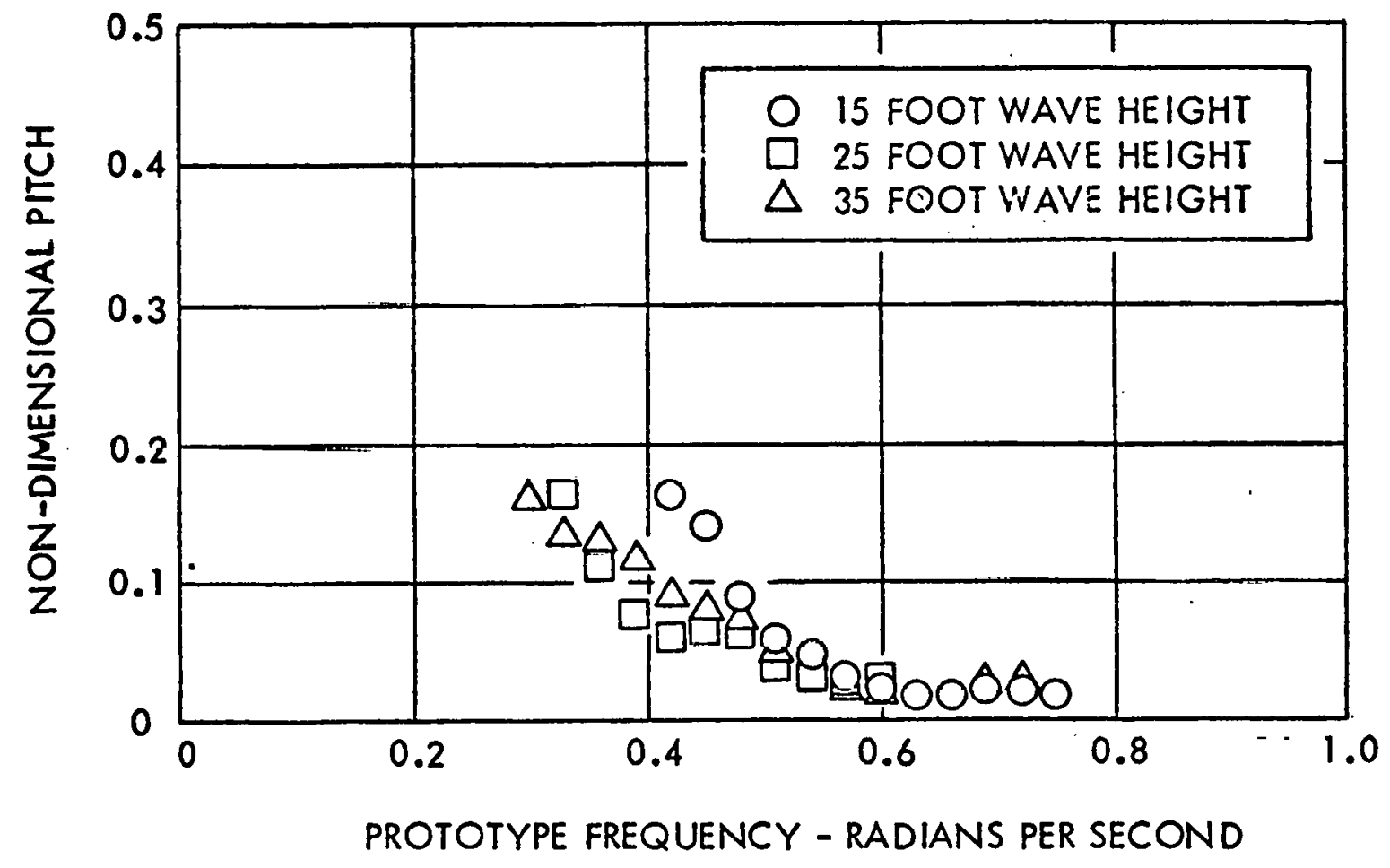

FIGURE 14 - MEASURED RAOS FOR PITCH - SPAR WITH PIN CONNECTED CWP 


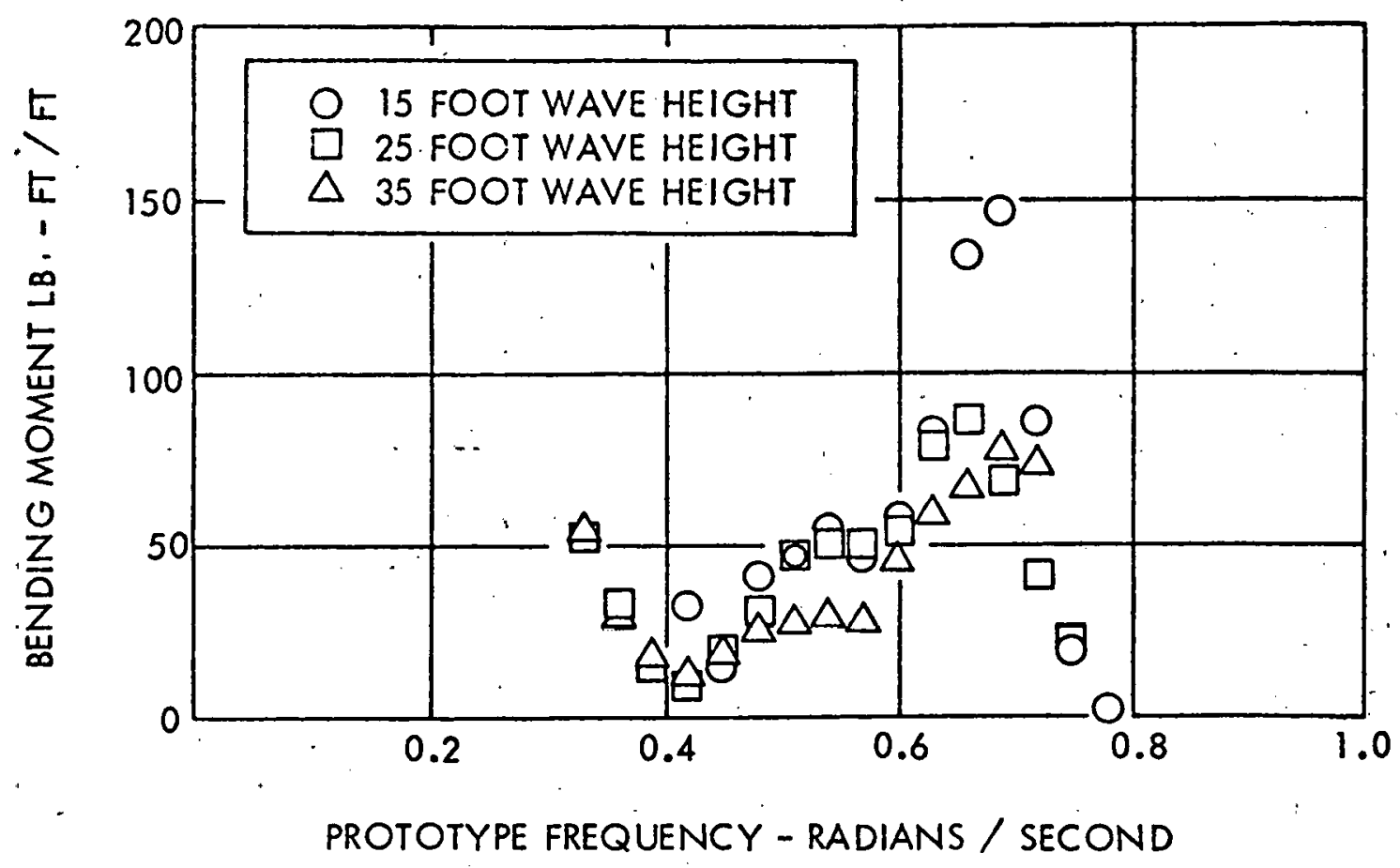

FIGURE 15 - MEASURED RAOS FOR BENDING MOMENT NO. 2 SPAR WITH PIN CONNECTED CWP

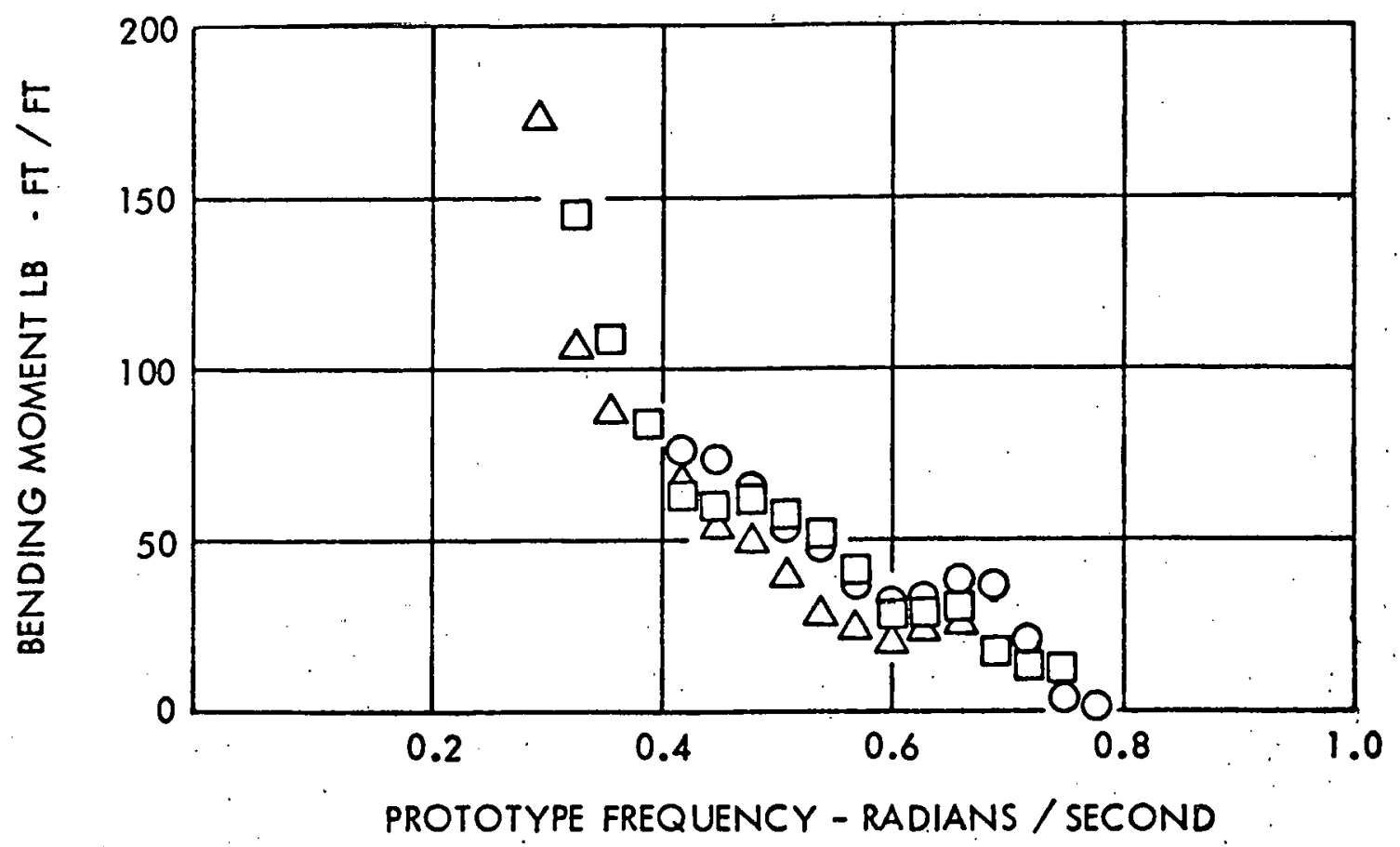

FIGURE 16 - MEASURED RAOS.FOR BENDING MOMENT NO. 3 SPAR WITH PIN CONNECTED CWP 
HYDRONAUTICS, INCORPORATED

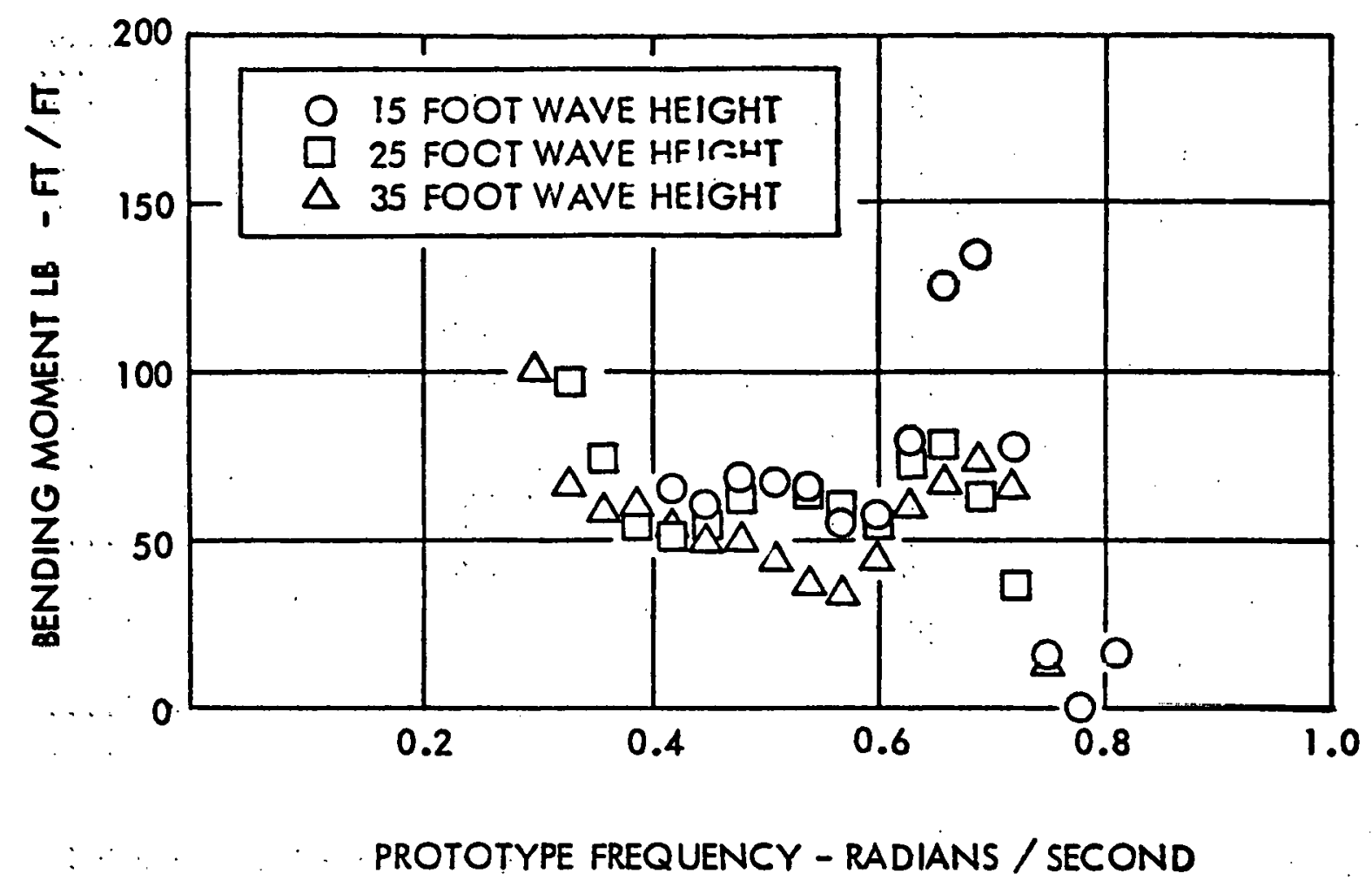

FIGURE 17 - MEASURED RAOS FOR BENDING MOMENT NO. 4 SPAR WITH PIN CONNECTED CWP 


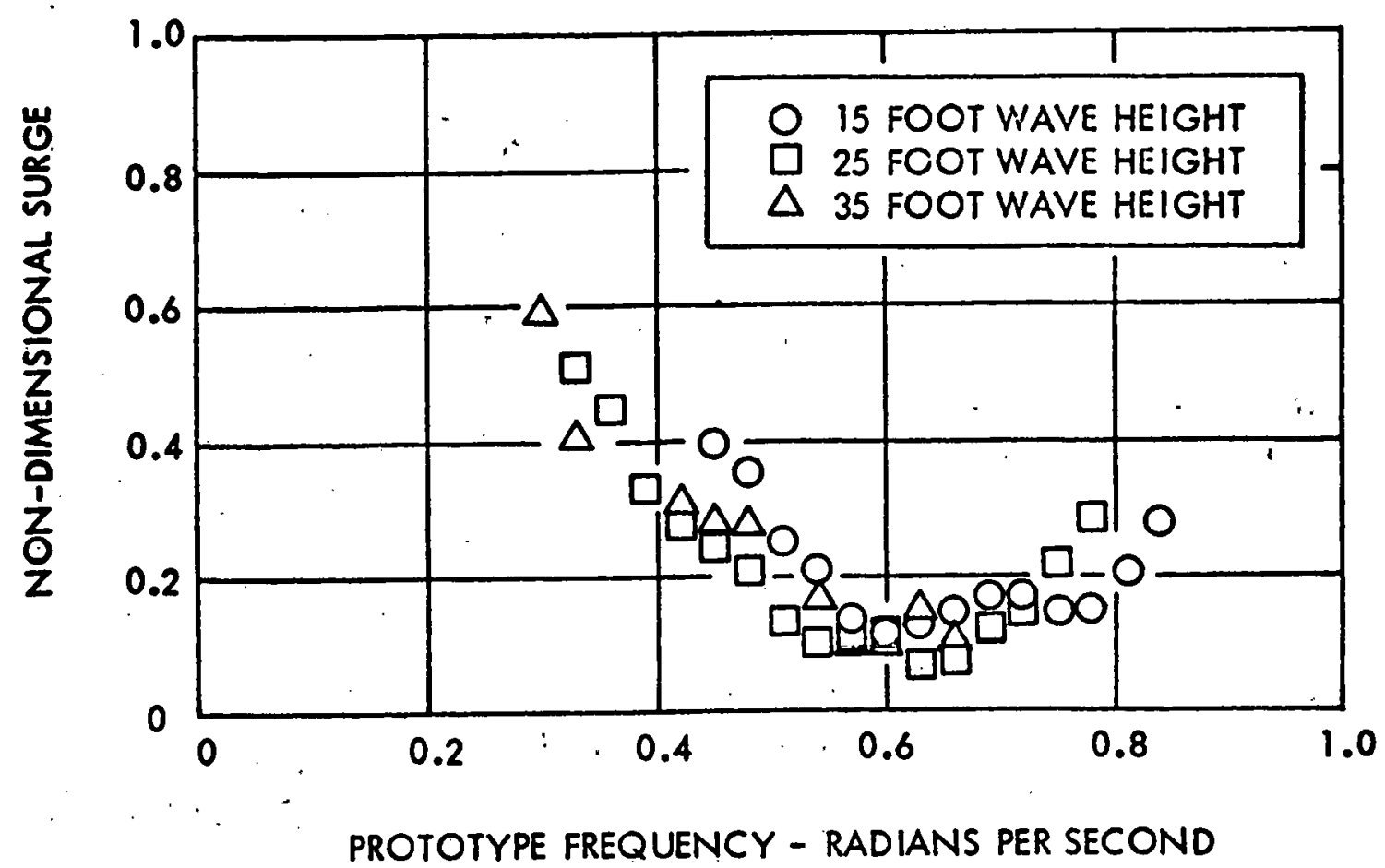

FIGURE 18 - MEASURED RAOS FOR SURGE - SPAR WITH RIGIDLY CONNECTED CWP

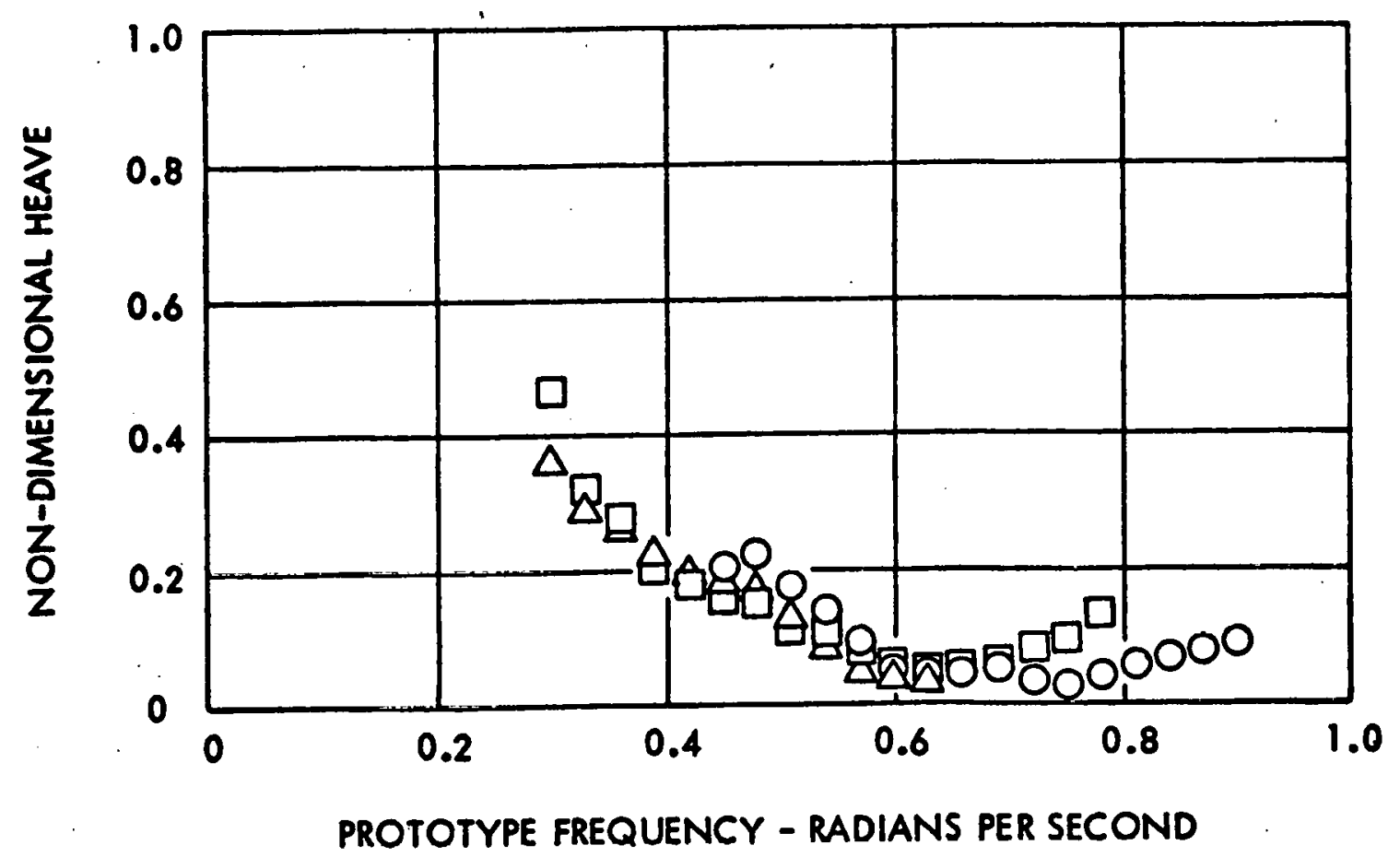

FIGURE 19 - MEASURED RAOS FOR HEAVE - SPAR WITH RIGIDLY CONNECTED CWP 
HYDRONAUTICS, INCORPORATED

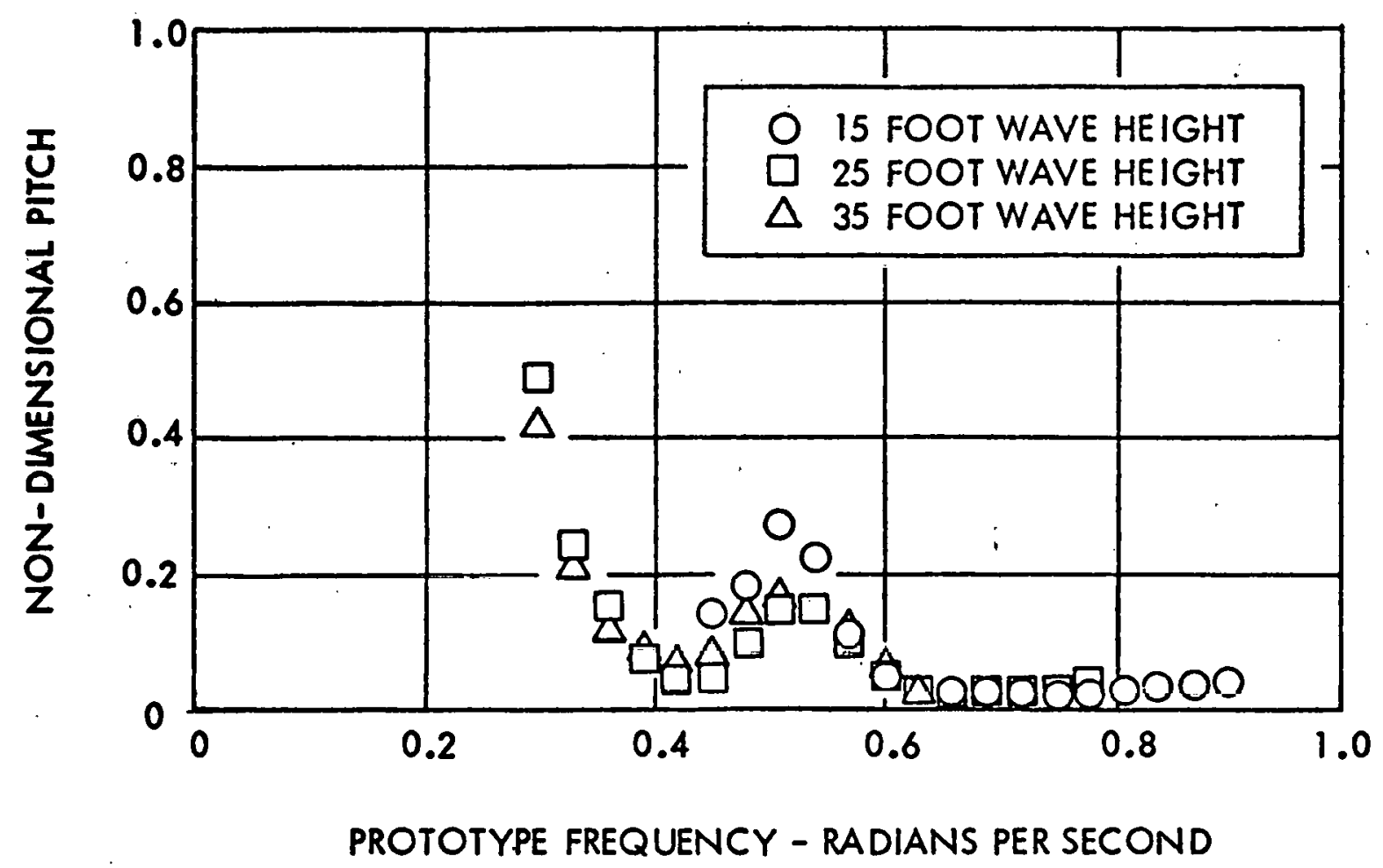

FIGURE 20 - MEASURED RAOS FOR PITCH - SPAR WITH RIGIDLY CONNECTED CWP 


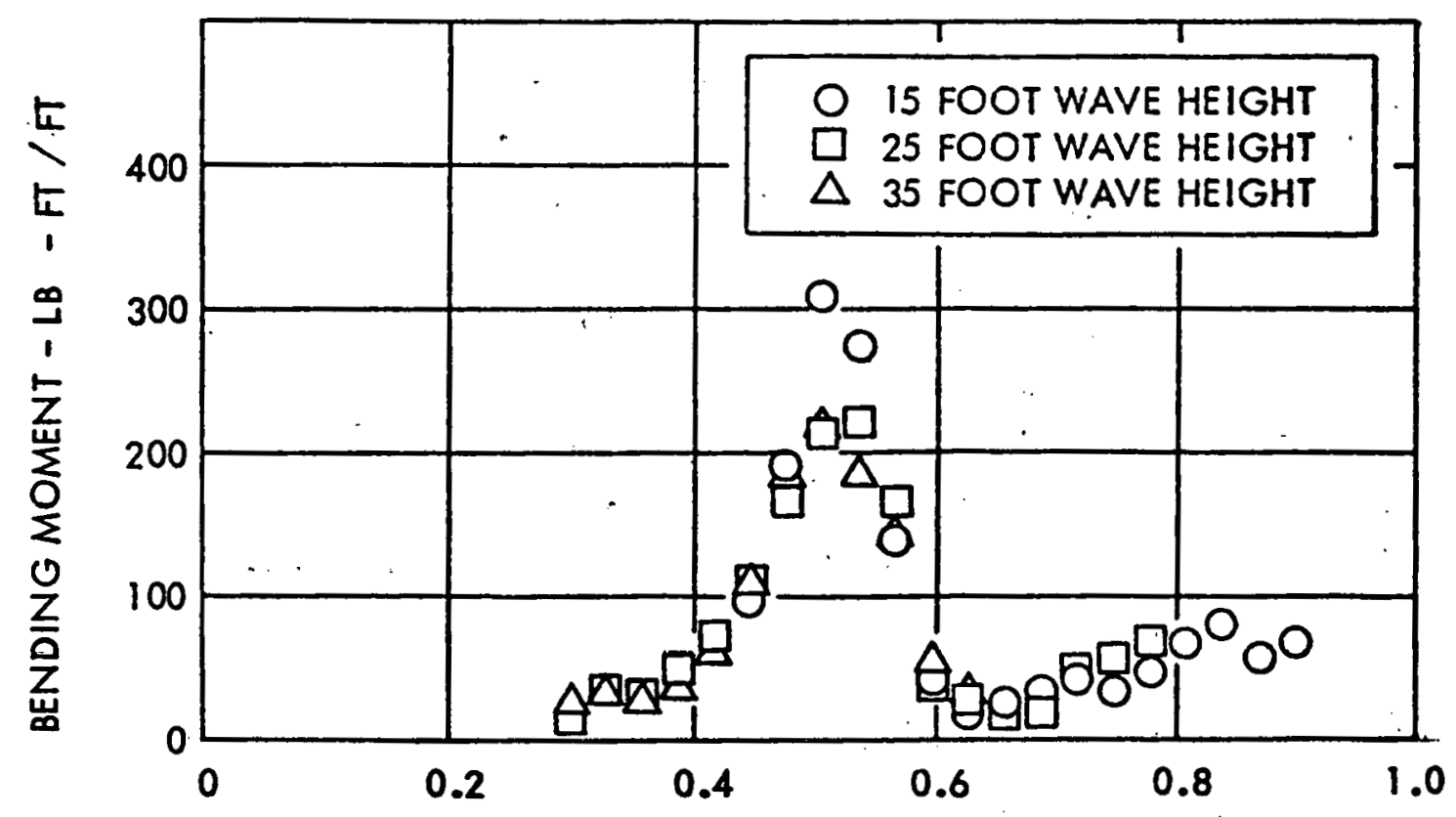

PROTOTYPE FREQUENCY - RADIANS / SECOND

FIGURE 21 - MEASURED RAOS FOR BENDING MOMENT NO. 1 SPAR WITH RIGIDLY CONNECTED CWP

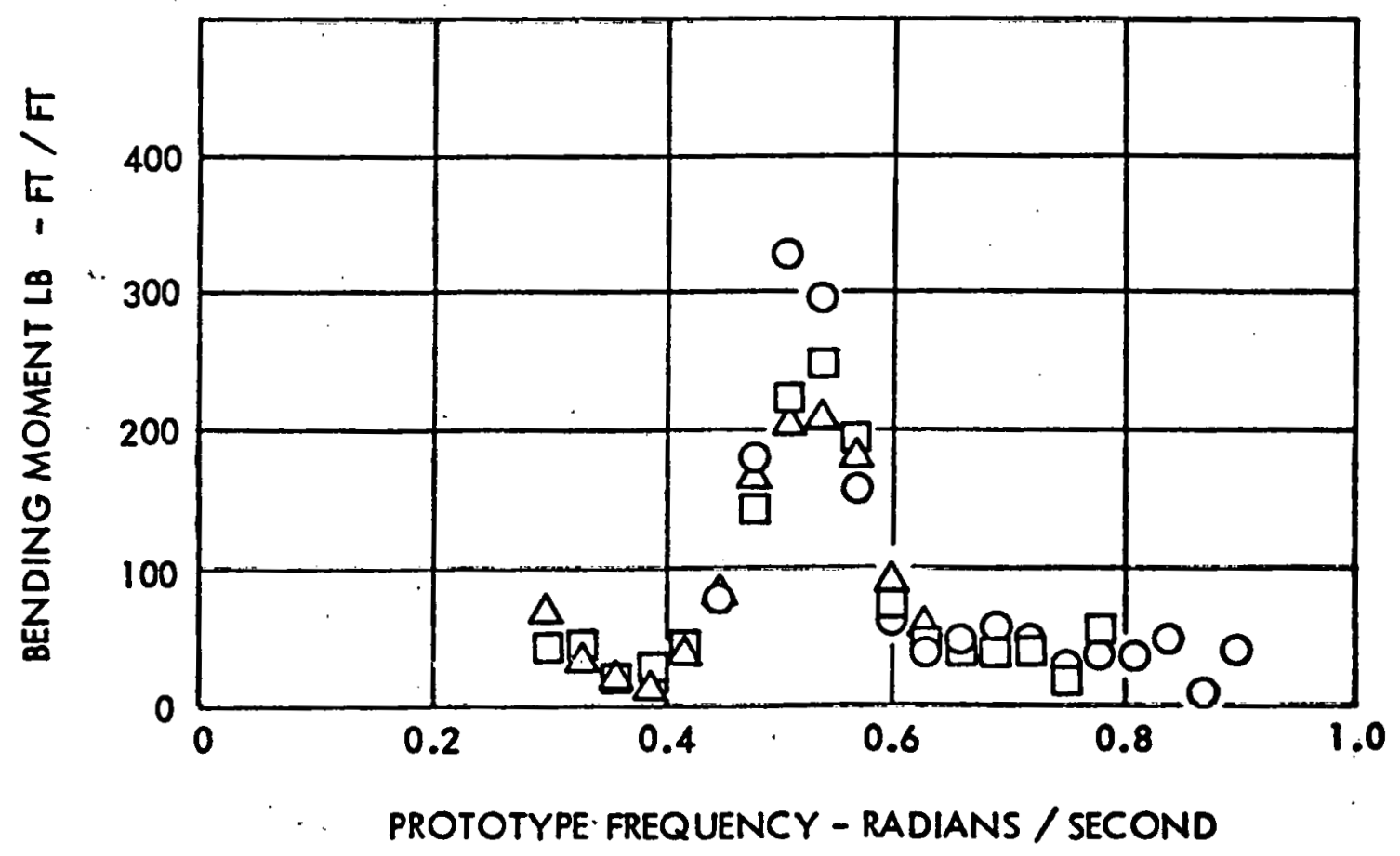

FIGURE 22 - MEASURED RAOS FOR BENDING MOMENT NO. 2 SPAR WITH RIGIDLY CONNECTED CWP 
HYDRONAUTICS, INCORPORATED -48-

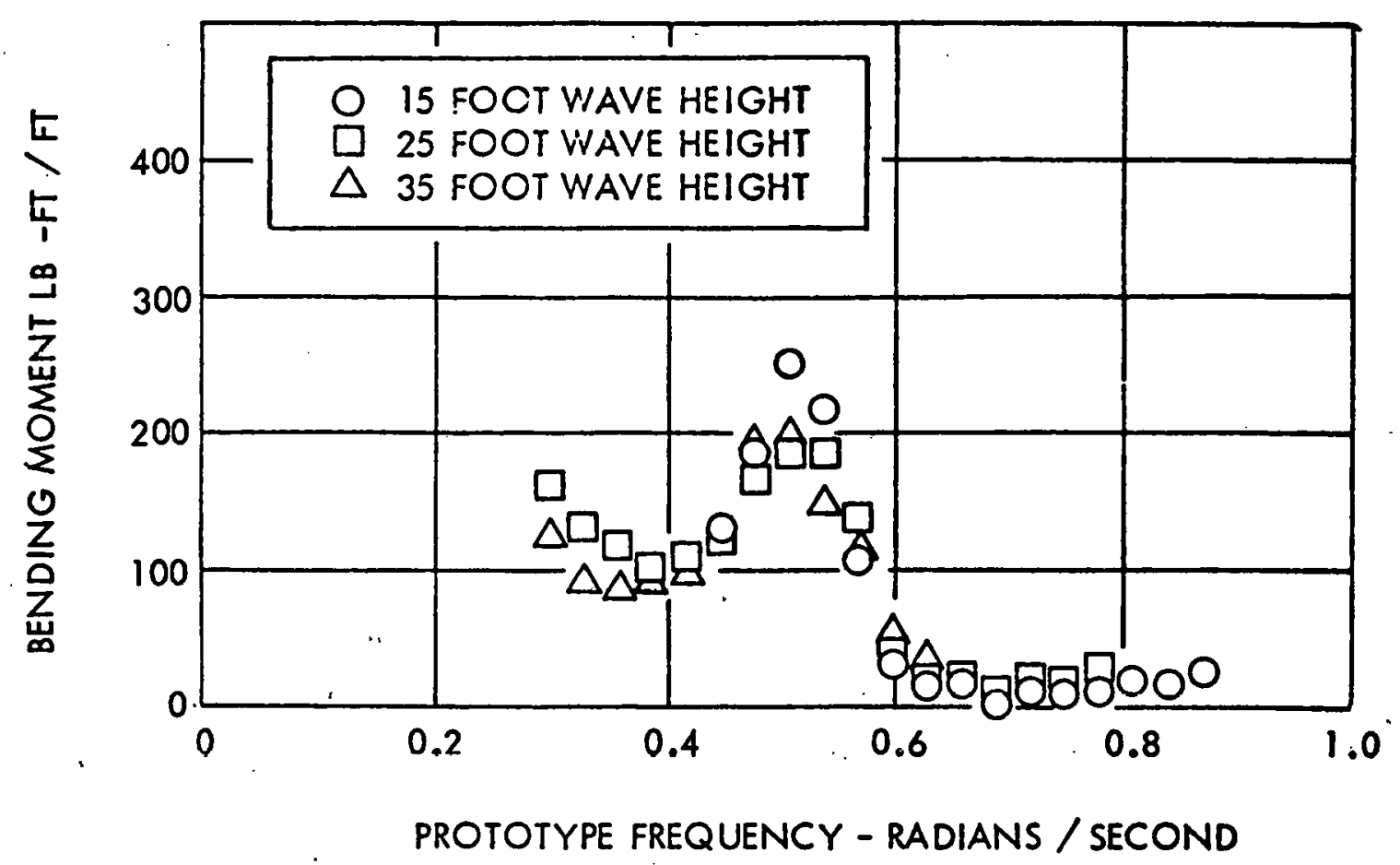

FIGURE 23 - MEASURED RAOs FOR BENDING MOMENT NO. 3 SPAR WITH RIGIDLY CONNECTED CWP

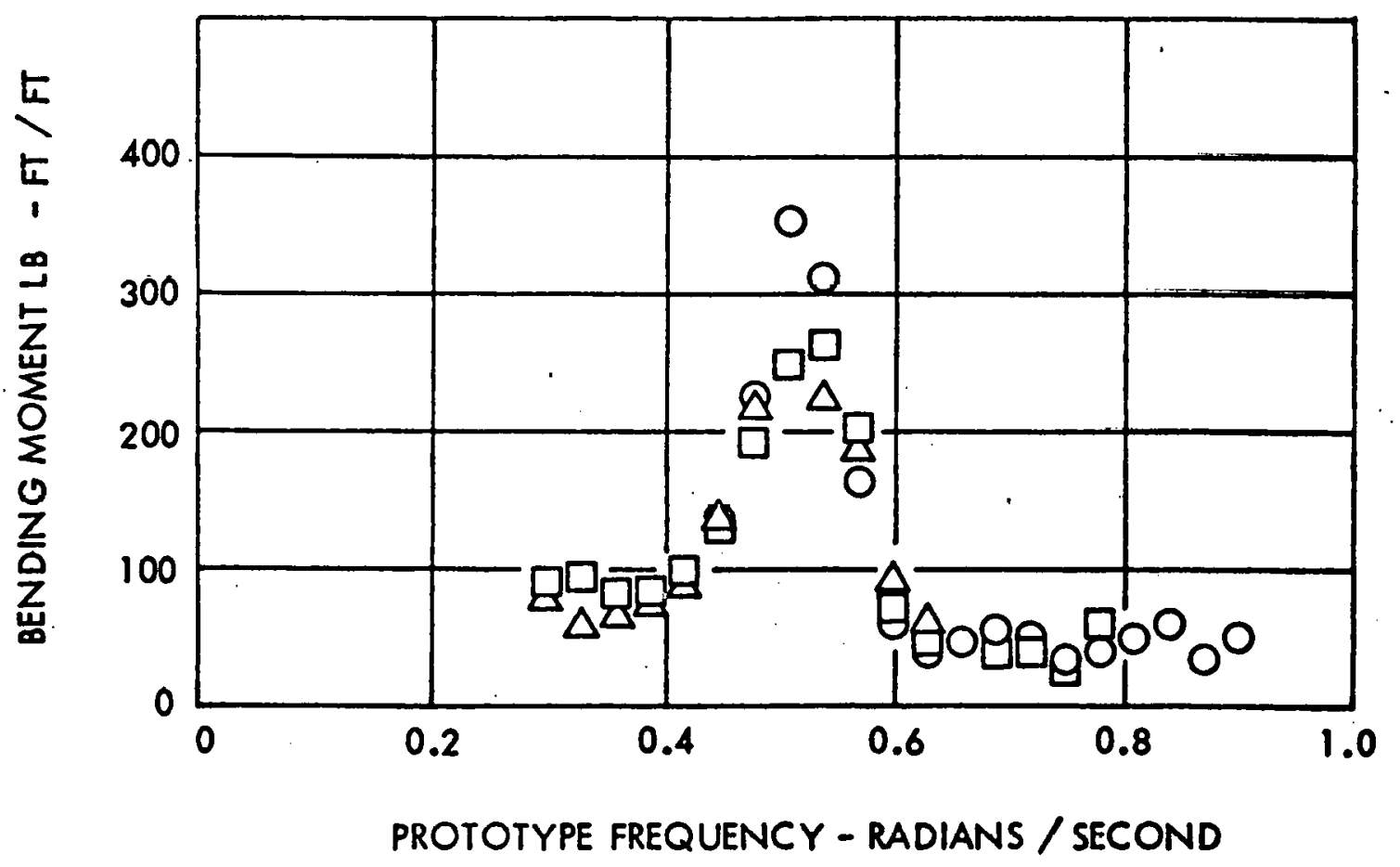

FIGURE 24 - MEASURED RAOS FOR BENDING MOMENT NO. 4 SPAR WITH RIGIDLY CONNECTED CWP 
HYDRONAUTICS, INCORPORATED

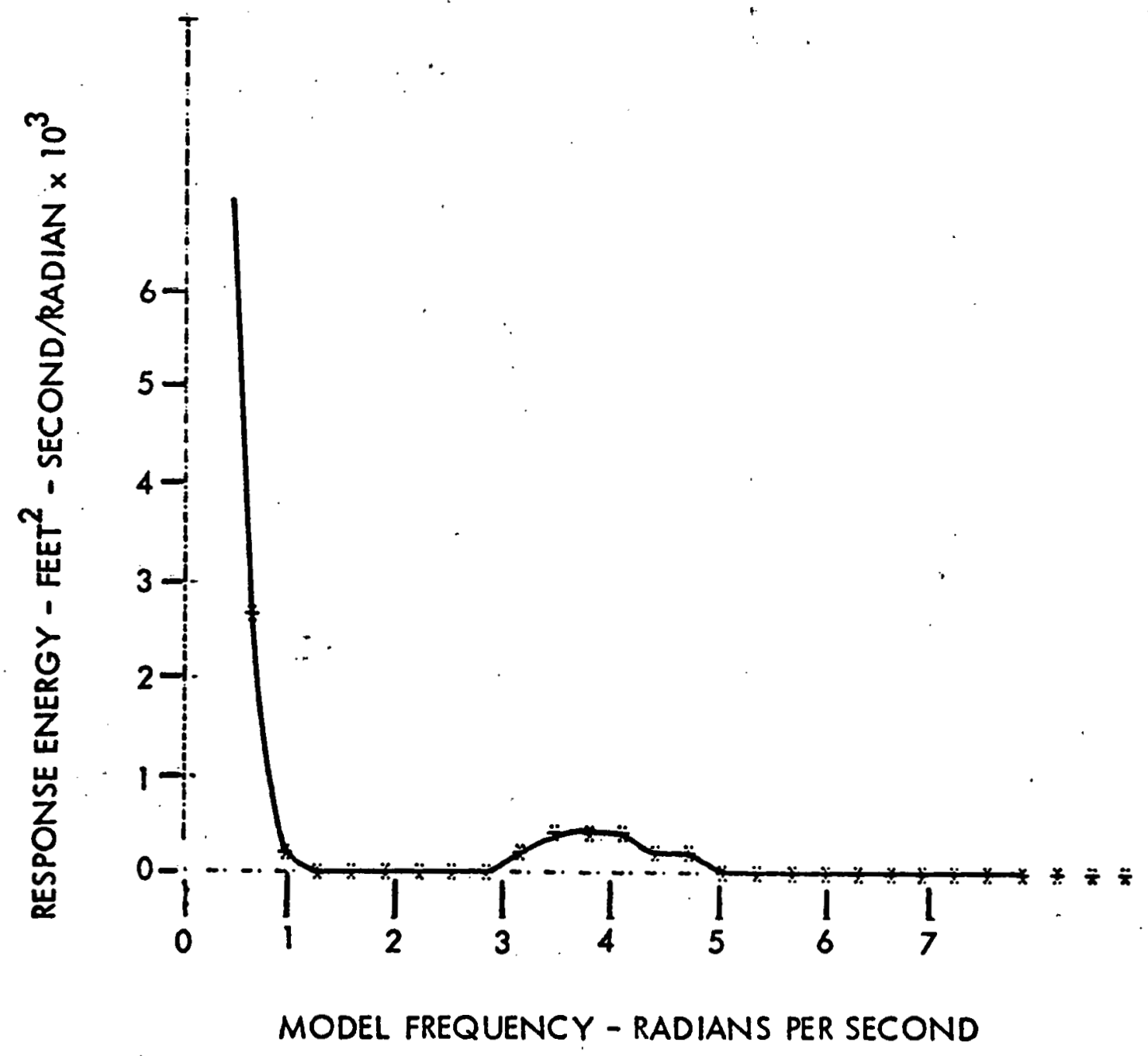

FIGURE 25 - TYPICAL HEAVE MOTION SPECTRUM 


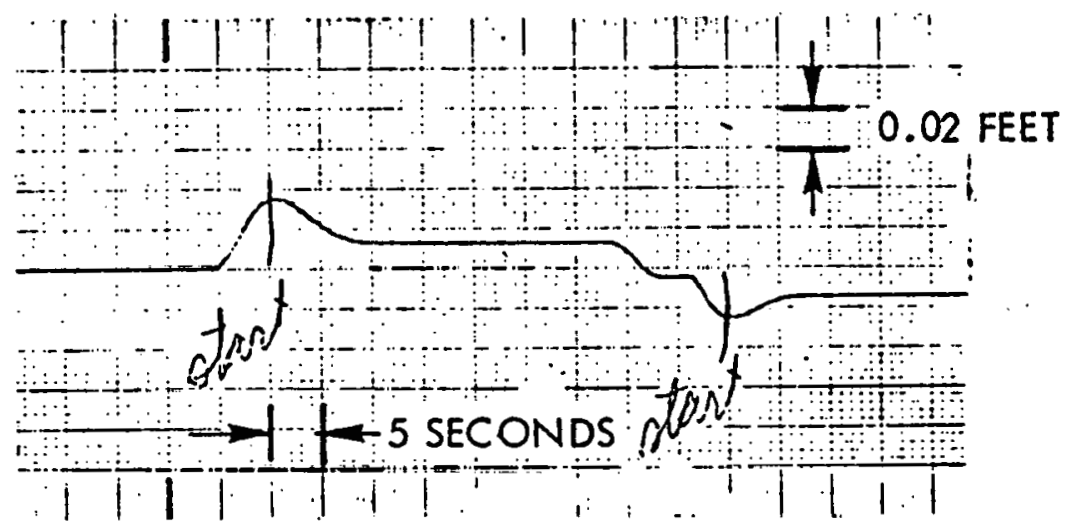

a. heAVE OSCILLATIONS

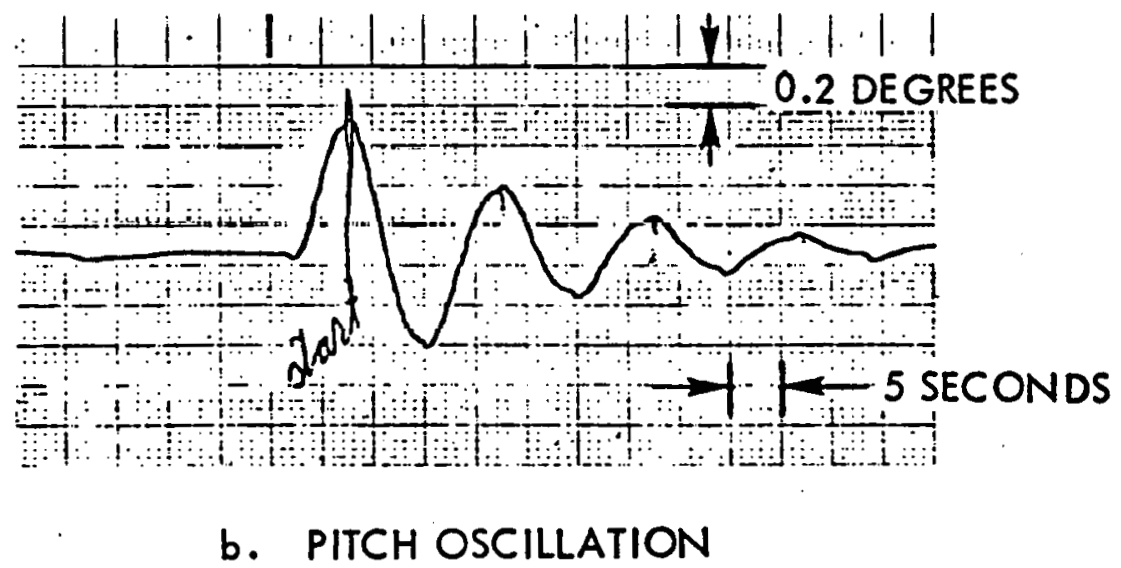

FIGURE 26 - TRACES OF FREE OSCILLATION TESTS 


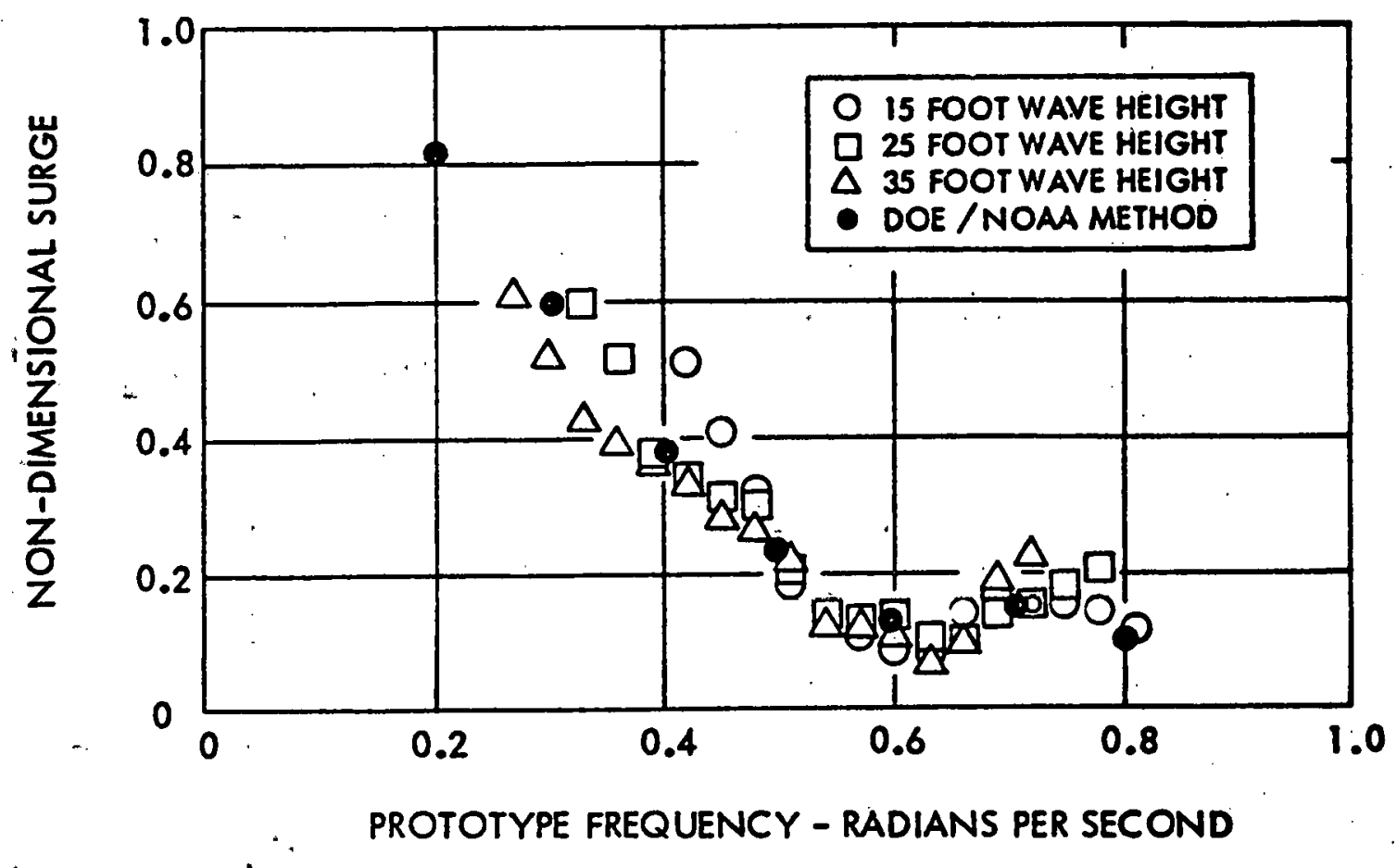

FIGURE 27 - COMPARISON OF CALCULATED AND MEASURED SURGE - SPAR ALONE

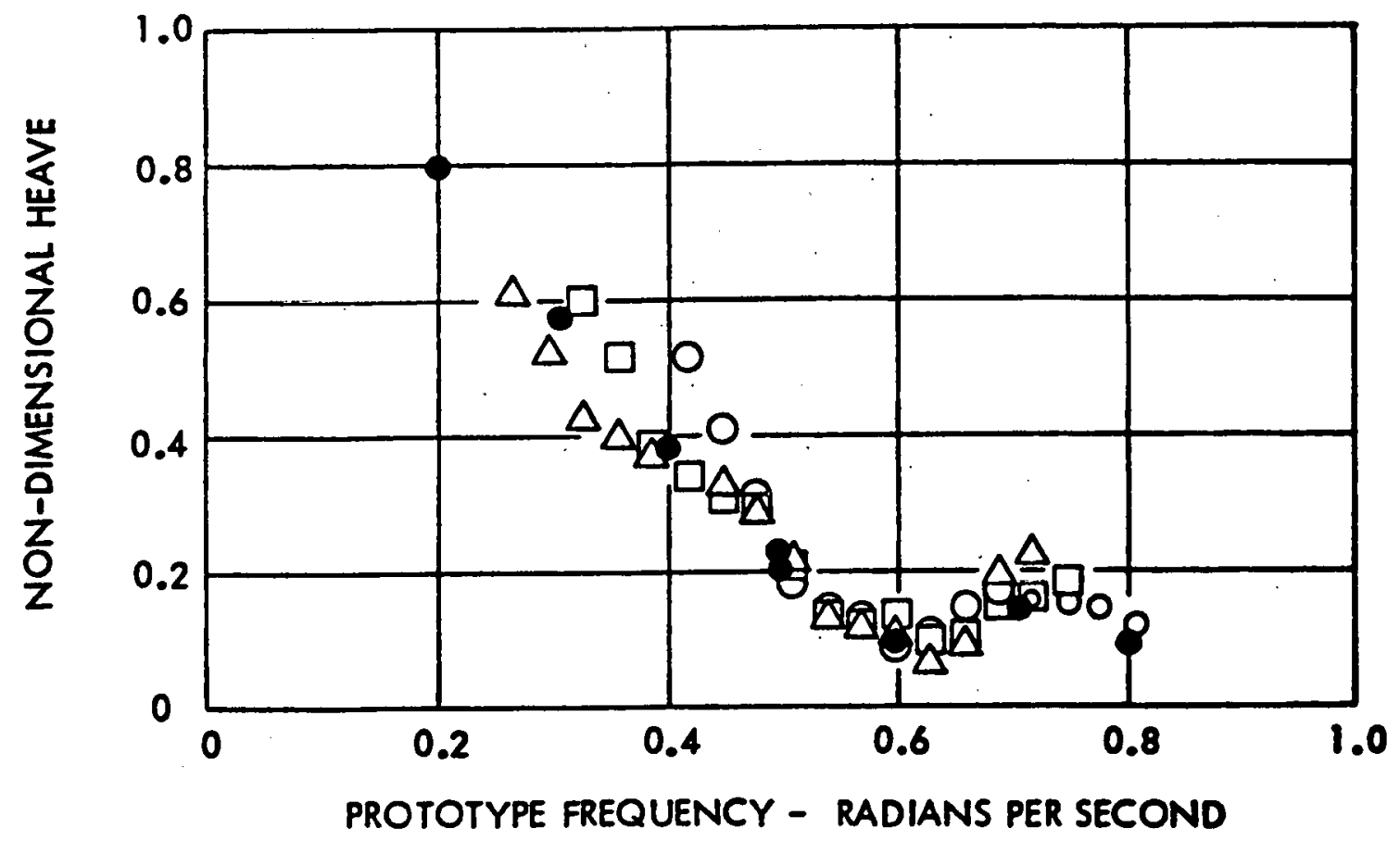

FIGURE 28 - COMPARISON OF CALCULATED AND MEASURED HEAVE - SPAR ALONE 


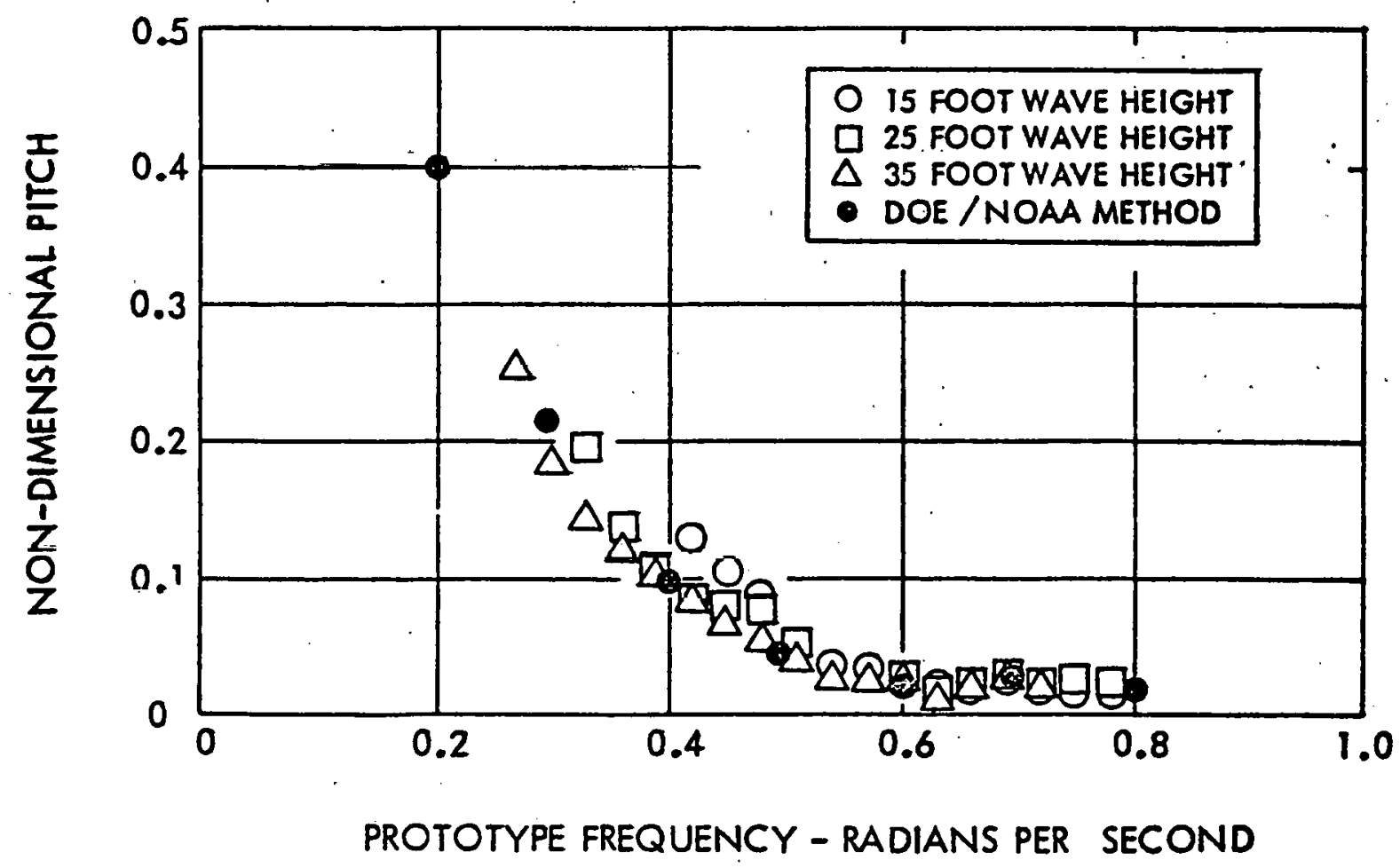

FIGURE 29 - COMPARISON OF CALCULATED AND MEASURED PITCH - SPAR ALONE 


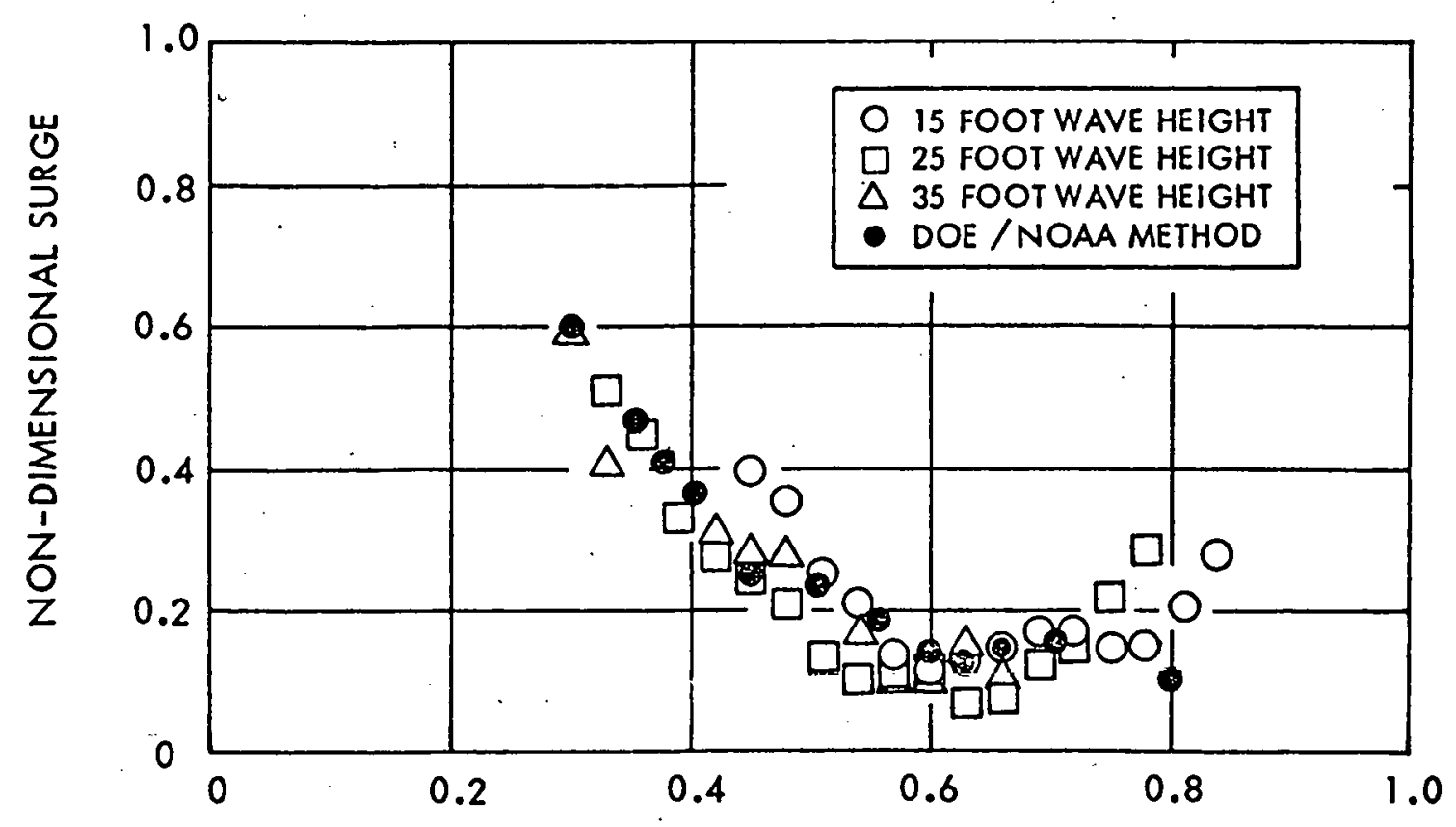

PROTOTYPE FREQUENCY - RADIANS PER SECOND

FIGURE 30 - COMPARISON OF CALCULATED AND MEASURED SURGE - SPAR WITH RIGIDLY ATTACHED CWP

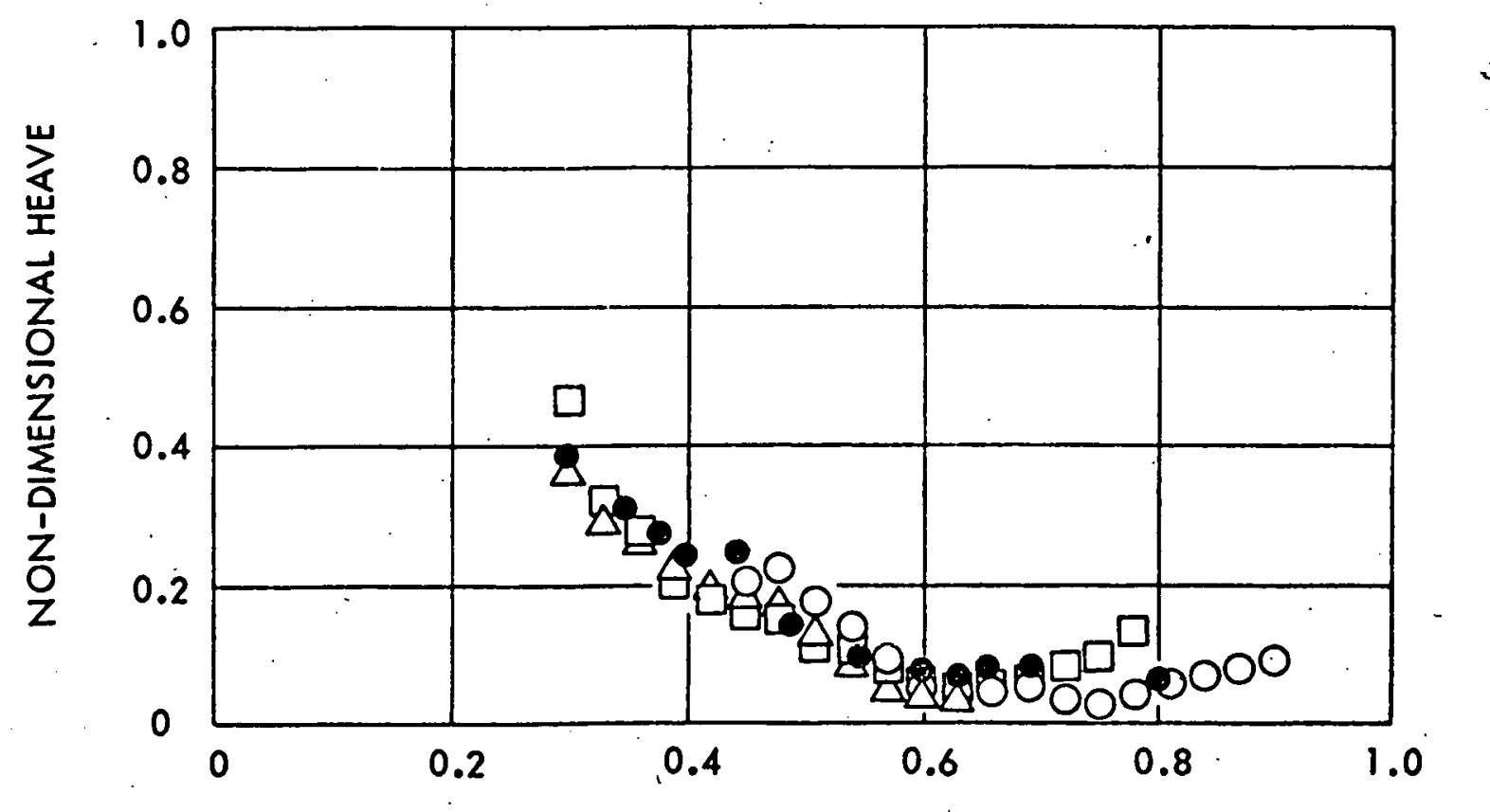

PROTOTYPE FREQUENCY - RADIANS PER SECOND

FIGURE 31 - COMPARISON OF CALCULATED AND MEASURED HEAVE - SPAR WITH RIGIDLY ATTACHED CWP 
HYDRONAUTICS, INCORPORATED

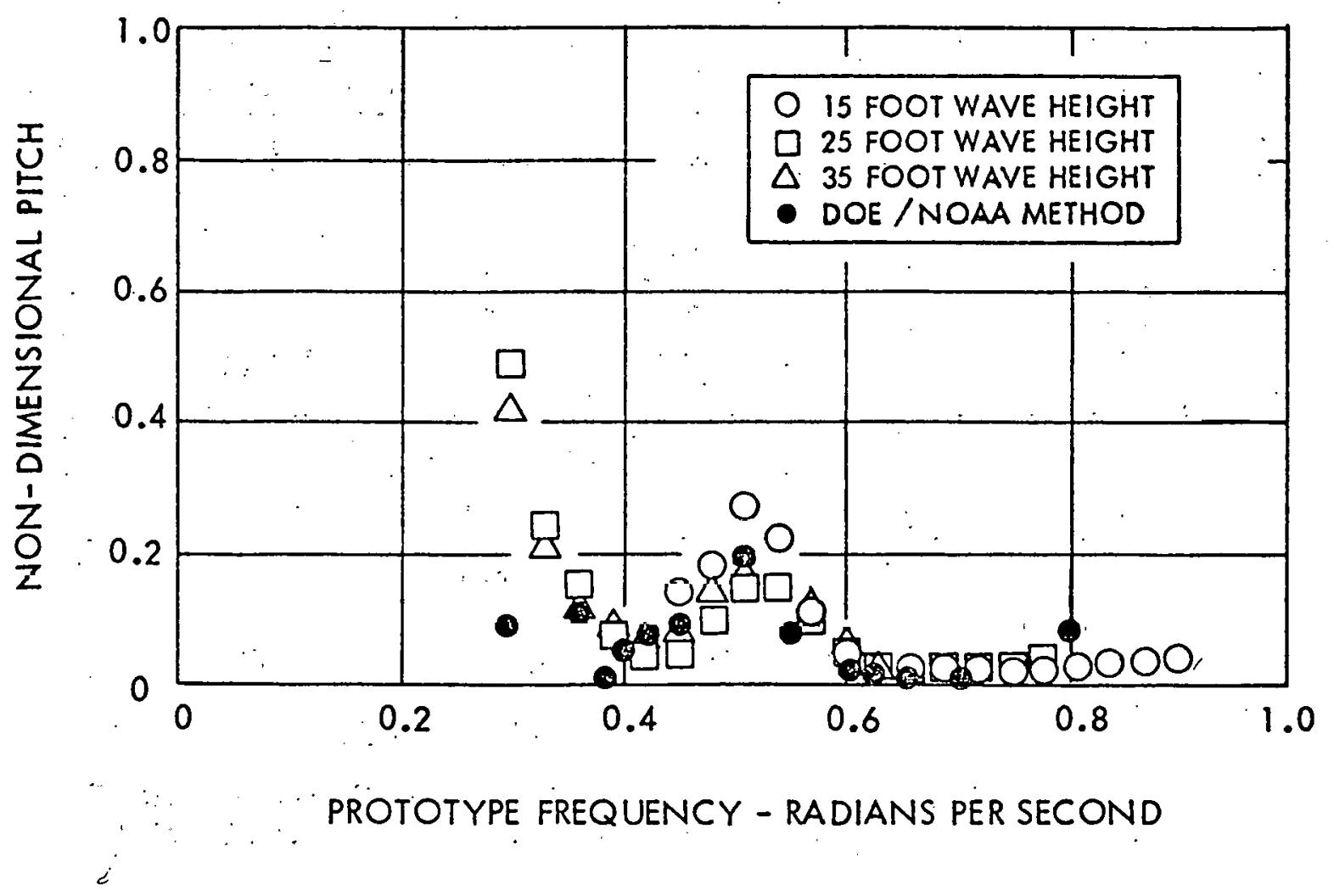

FIGURE 32 - COMPARISON OF CALCULATED AND MEASURED PITCH - SPAR WITH RIGIDLY ATTACHED CWP 


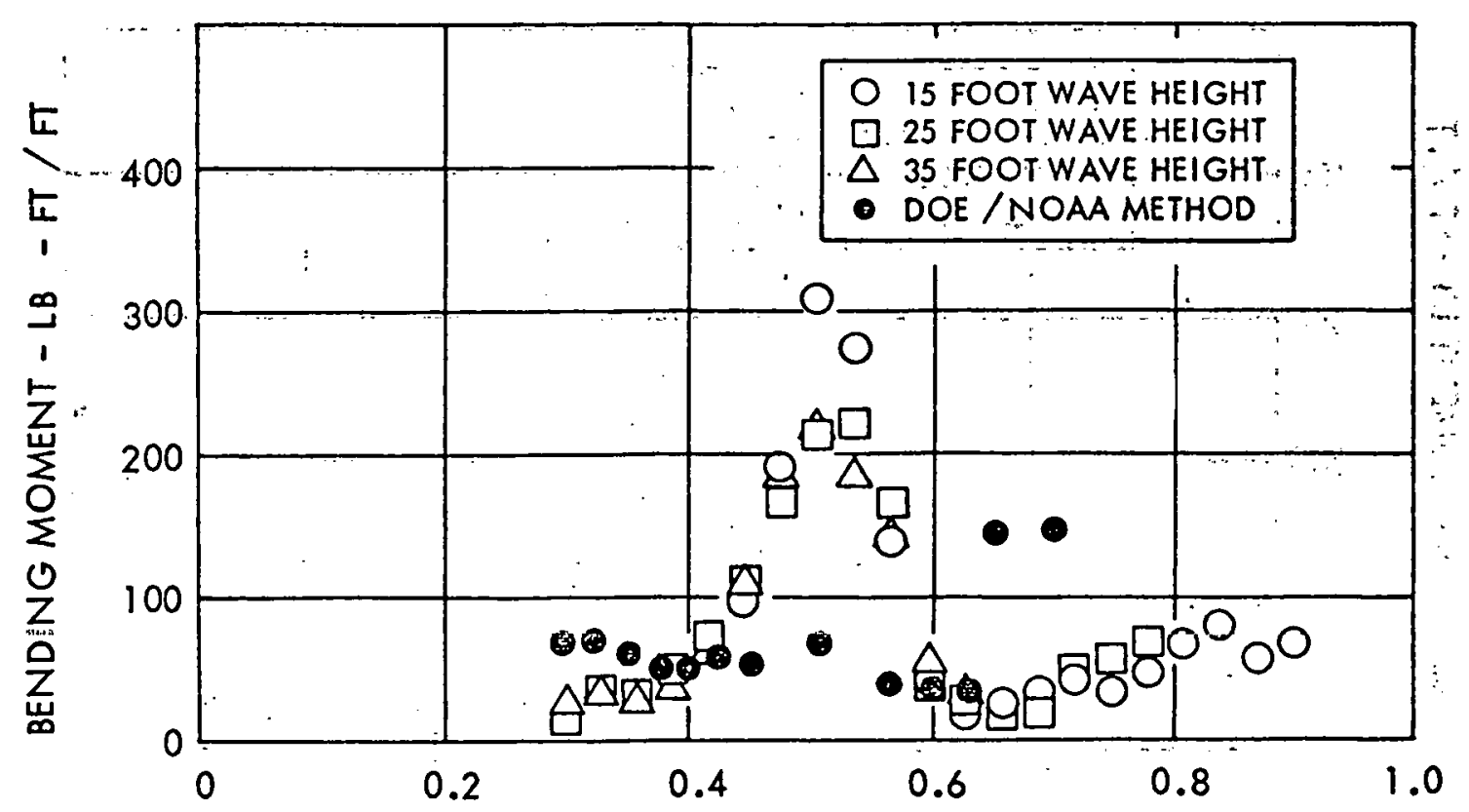

PROTOTYPE FREQUENCY - RADIANS / SECOND

FIGURE 33 - COMPARISON OF BENDING MOMENT NO. 1 SPAR WITH RIGIDLY ATTACHED CWP

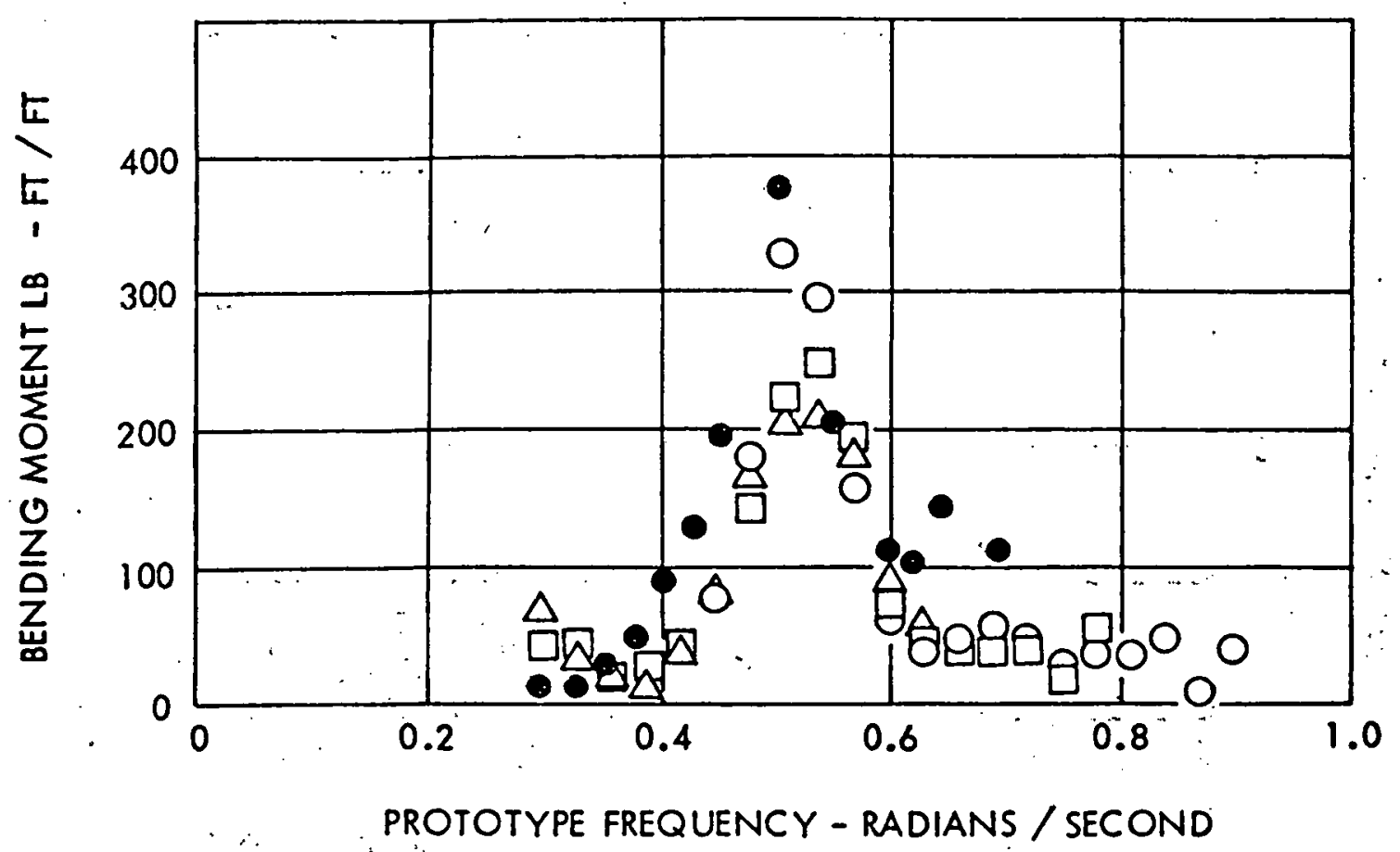

FIGURE 34 - COMPARISON OF BENDING MOMENT NO. 2 SPAR WITH RIGIDLY ATTACHED CWP 


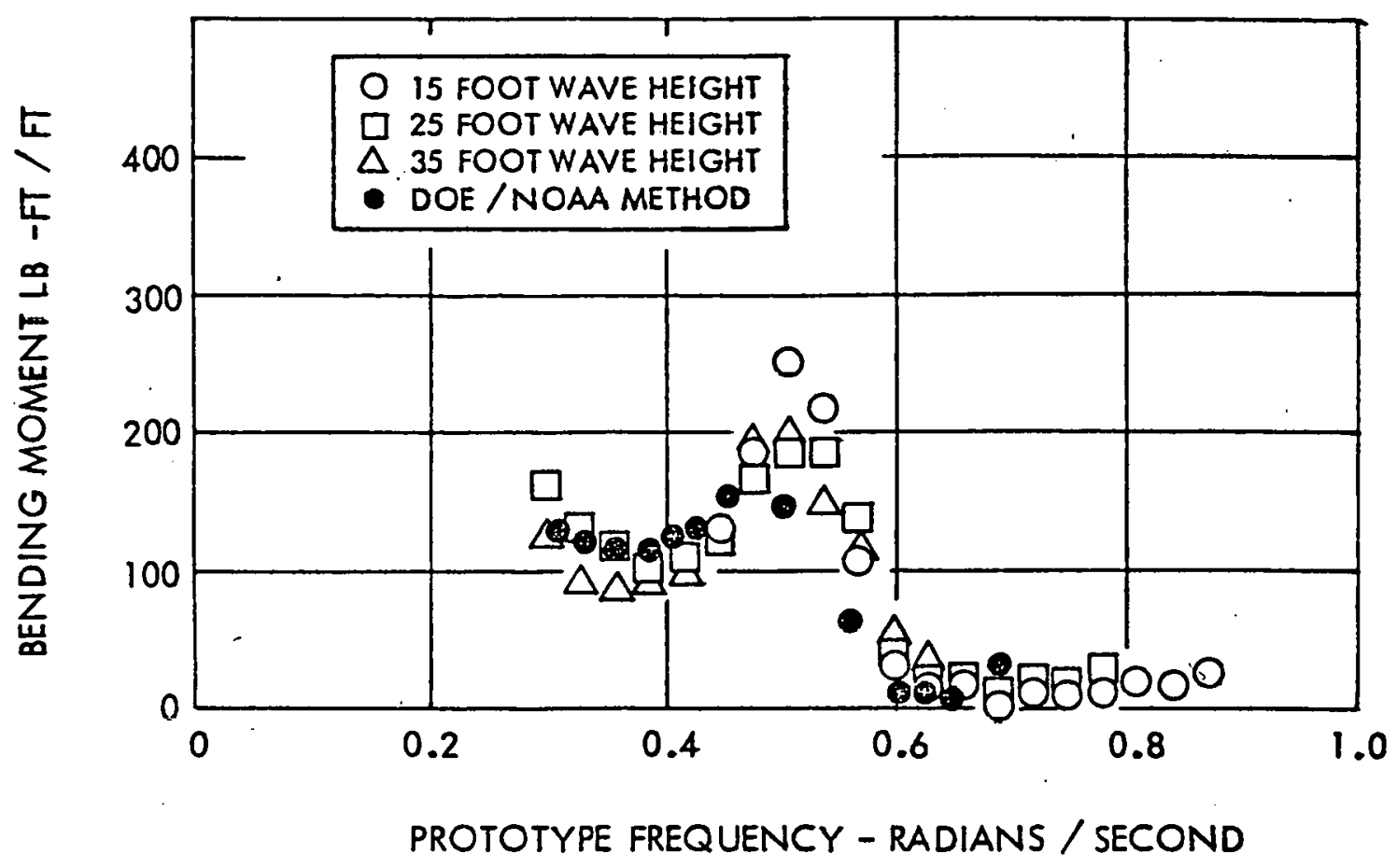

FIGURE 35 - COMPARISON OF BENDING MOMENT NO. 3 SPAR WITH RIGIDLY ATTACHED CWP

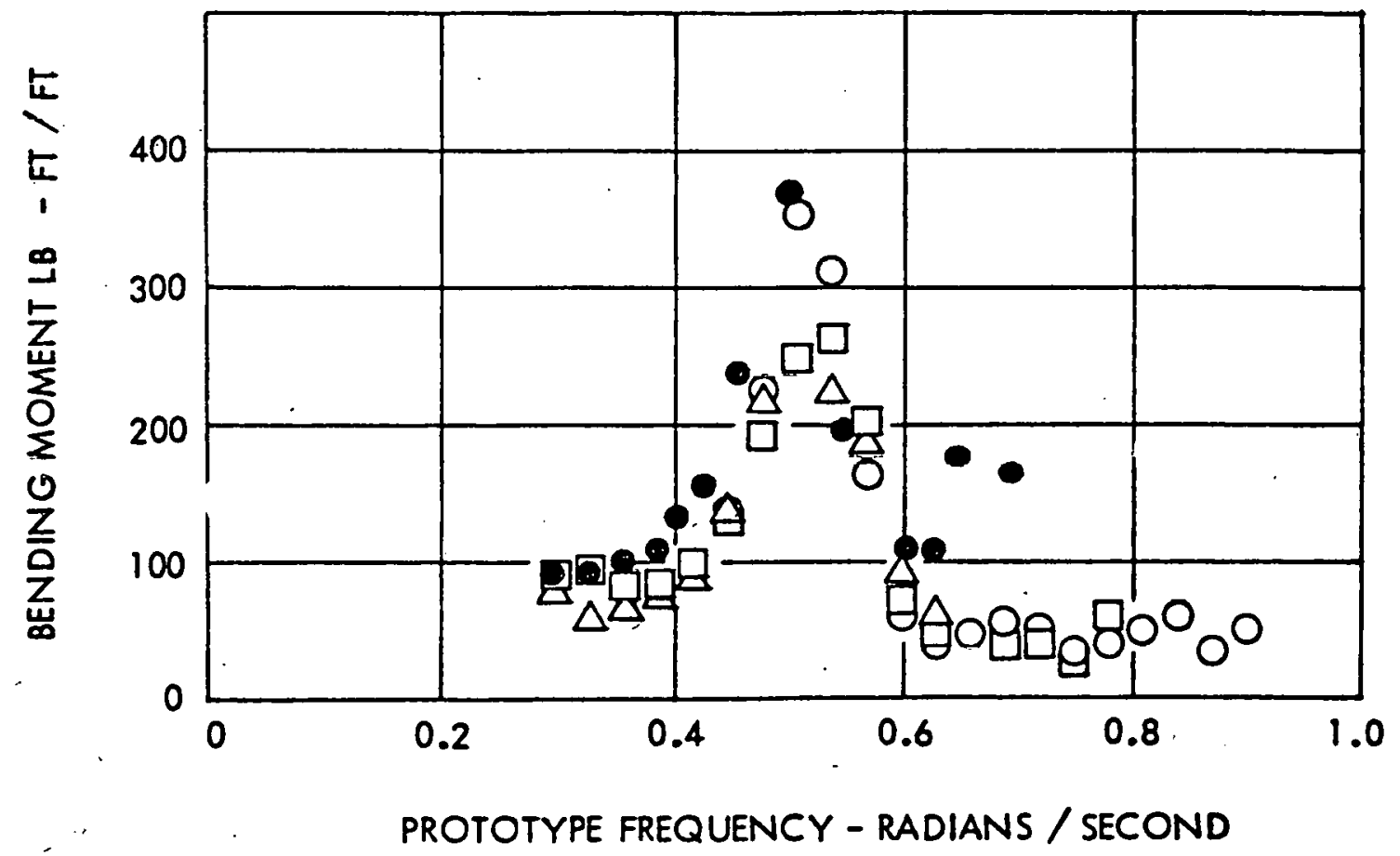

FIGURE 36 - COMPARISON OF BENDING MOMENT NO. 4 SPAR WITH RIGIDLY ATTAEHED CWP 